\title{
Mitochondrial Dysfunction and Inflammaging in Heart Failure: Novel Roles of CYP-Derived Epoxylipids
}

\author{
Hedieh Keshavarz-Bahaghighat ${ }^{1}$, Ahmed M. Darwesh ${ }^{1}$, Deanna K. Sosnowski ${ }^{1}{ }^{10}$ and \\ John M. Seubert ${ }^{1,2,3, *}$ \\ 1 Faculty of Pharmacy and Pharmaceutical Sciences, University of Alberta, Edmonton, AB T6G 2E1, Canada; \\ hkeshava@ualberta.ca (H.K.-B.); darweshe@ualberta.ca (A.M.D.); dksosnow@ualberta.ca (D.K.S.) \\ 2 Department of Pharmacology, Faculty of Medicine and Dentistry, University of Alberta, Edmonton, \\ AB T6G 2E1, Canada \\ 3 Faculty of Pharmacy and Pharmaceutical Sciences, University of Alberta 2020-M Katz Group Centre for \\ Pharmacy and Health Research 11361-87 Avenue, Edmonton, AB T6G 2E1, Canada \\ * Correspondence: jseubert@ualberta.ca; Tel.: +780-492-0007
}

Received: 21 May 2020; Accepted: 24 June 2020; Published: 27 June 2020

check for updates

\begin{abstract}
Age-associated changes leading to a decline in cardiac structure and function contribute to the increased susceptibility and incidence of cardiovascular diseases (CVD) in elderly individuals. Indeed, age is considered a risk factor for heart failure and serves as an important predictor for poor prognosis in elderly individuals. Effects stemming from chronic, low-grade inflammation, inflammaging, are considered important determinants in cardiac health; however, our understanding of the mechanisms involved remains unresolved. A steady decline in mitochondrial function is recognized as an important biological consequence found in the aging heart which contributes to the development of heart failure. Dysfunctional mitochondria contribute to increased cellular stress and an innate immune response by activating the NLRP-3 inflammasomes, which have a role in inflammaging and age-related CVD pathogenesis. Emerging evidence suggests a protective role for CYP450 epoxygenase metabolites of N-3 and N-6 polyunsaturated fatty acids (PUFA), epoxylipids, which modulate various aspects of the immune system and protect mitochondria. In this article, we provide insight into the potential roles N-3 and N-6 PUFA have modulating mitochondria, inflammaging and heart failure.
\end{abstract}

Keywords: aging; inflammasome; heart failure; mitochondria; N-3 and N-6 polyunsaturated fatty acids; epoxylipids

\section{Introduction}

Aging is a key determinant of cardiovascular health, as evidenced from an exponential increase in the prevalence of cardiovascular disease (CVD) in the geriatric population [1]. Aging hearts can be characterized by overall decreased function, reduced cardiac reserve capacity, structural remodeling and electrical dysfunction [2,3]. The extent and duration of exposure to extrinsic risk factors linked to development of CVD, including hypertension, diabetes and smoking increases with time, thereby contributing to increased cardiovascular morbidity and mortality in aged individuals [4,5]. In addition, naturally occurring biological aging events lead to the slow progressive deterioration in cardiac structure and function in the absence of systemic risk factors [6]. In essence, the age-associated extrinsic and intrinsic changes converge to accelerate a deterioration of cardiac function and structure contributing to the increased susceptibility and incidence of CVD in elderly. 
Heart failure (HF) is a growing healthcare burden and the leading cause of hospitalization and readmissions [7]. HF is a clinical syndrome attributed to impaired ventricular filling or ejection of blood that can result from any abnormality in cardiac function and structure leading to an inability to adequately meet the hemodynamic requirements of the body at rest or with stress [8-10]. Heart failure is associated left ventricular (LV) dysfunction ranging from patients with normal LV structure and ejection fraction (EF) to those with severe LV dilation and reduced EF [10]. Based on EF, the guidelines classify HF into three categories: patients with preserved LVEF ( $\geq 50 \%$, HFpEF), patients with mid-range EF (41-49\%, HFmEF) and patients with reduced EF ( $\leq 40 \%, \mathrm{HFrEF})$ [9]. Epidemiological studies from patients with HF have reported that the proportion of patients with HFpEF is exceeding the number of those with HFrEF over recent years [11-13]. While HFpEF has a complex and heterogenous pathophysiology, ventricular diastolic dysfunction is considered the major outcome of the disease. The ventricular diastolic dysfunction is manifested as impaired diastolic relaxation accompanied by increased diastolic stiffness leading to abnormalities in ventricular filling dynamics [14]. Notably, these cardiac anomalies are aggravated by exposure to stress such as tachycardia, hypertension and even during exercise as EF does not increase proportionally with stress leading to impairment of systolic function [15-18]. Accumulating experimental and translational evidence demonstrated development of HFpEF cannot be attributed to a single cause; however, several factors contribute to the pathology [19]. For instance, vascular stiffness, systemic inflammation, as well as the presence of comorbid conditions such as diabetes mellitus and pulmonary hypertension, among others, have been implicated in the development of the disease [20]. The prevalence of HFpEF increases with age and is more prominent in women [21,22]. There are several age-related alterations in cardiovascular function and structure, such as atrial stiffening, vascular fibrosis and thickening, LV hypertrophy, and insufficient mitochondrial energy production. These distinctive changes may partly explain why elderly individuals are more likely to develop HFpEF $[23,24]$. However, because of inconsistent diagnostic criteria, limited understanding of pathogenesis, insufficient available data from human tissues, and lack of appropriate animal models, our understanding about the cellular and molecular mechanisms involved in HFpEF pathophysiology remains limited $[25,26]$.

Regardless of LVEF, patients with HF have increased risk of mortality compared to those without HF [25]. The chief manifestations of HF are dyspnea, fatigue and exercise intolerance resulting from cardiac structural and functional abnormalities that lead to elevated intra-cardiac pressure or a reduced cardiac output $[27,28]$. Epidemiological studies show a growing prevalence of HF in the elderly, with people 65 years old and older constituting over $80 \%$ of the patients $[29,30]$. While aging itself does not cause HF, evolving evidence suggests that the direct effects of myocardial aging contribute to the development and progression [31]. In patients with HF, age has been determined to be an independent factor associated with poor prognosis and higher risk of cardiovascular events and mortality [32,33]. Importantly, a marked increase in aging populations is occurring globally where individuals over 65 are beginning to account for larger percentages of the total populace [34]. Given the dramatic growth in the elderly population, age-related HF represents one of the greatest challenges confronting the health care system.

Chronic inflammation is a key component of aging and aging-related pathologies associated with increased risk of cardiovascular morbidity and mortality [35]. "Inflammaging" refers to chronic low-grade inflammation resulting from long term physiologic activation of the innate immune system in the absence of overt infections [36]. Potential mechanisms of inflammaging include genetic susceptibility, cellular senescence, impaired autophagy, changes to microbiota composition, oxidative stress and dysfunctional mitochondria [29,37,38]. Chronic inflammation contributes to the decline in cardiac function, increased size of cardiomyocytes and myocardial fibrosis, furthering the development and progression of HF $[39,40]$.

Studies in experimental animal models and human hearts suggest that mitochondria play a central role in the aging process and abnormalities in mitochondrial function and structure are considered major drivers of age-associated cardiac dysfunction $[3,40,41]$. In healthy myocardium, mitochondria provide 
up to $90 \%$ of energy demand of the beating heart by mediating electron transportation to generate ATP on a beat-to-beat basis [42]. Mismatch between ATP supply and demand attributed to mitochondrial dysfunction has been historically considered as the primary mechanism linking mitochondria to cardiovascular diseases [43-45]. However, the role of mitochondria is now increasingly recognized to reach far beyond a failed powerhouse $[46,47]$. Defective mitochondrial reactive oxygen species (ROS) handling has emerged as a central factor in pathogenesis of a wide variety of cardiovascular dysfunctions, including cardiac aging and HF [48]. Moreover, mitochondria are emerging as key players in regulation of innate immunity. Studies on mitochondrial-mediated regulation of inflammasomes and sterile inflammation in CVD have expanded increasingly in recent years [49-51]. Enhancing our understanding of inflammatory pathways interwoven with mitochondrial events in the process of cardiac aging remains important, notably toward developing more promising therapeutics for age-associated pathologies, including HF.

\section{NLRP3 Inflammasomes in Chronic Inflammation and Heart Failure}

A chronic low-grade inflammatory state involving the sustained activation of innate immune system is a key characteristic of cardiac aging [52]. The innate immune system comprises a non-specific arm of the host-defense representing an initial defensive response against invading pathogens and plays a central role in activating the adaptive immune response [53-55]. The innate immune system is activated through the recognition of pathogen associated molecular patterns (PAMPs) or damage associated molecular patterns (DAMPs) by specific receptors called pattern recognition receptors (PRRs), which are present in the extracellular and endosomal compartment [56]. While PAMPs are derived from microorganisms and initiate immune response to infections, DAMPs stem from host cells and are released in response to cellular stress or tissue damage $[57,58]$. The engagement of PPRs initiates signaling pathways that lead to release of pro-inflammatory cytokines, migration of additional innate immune cells and activation of the adaptive immune system mediated by $B$ and $T$ cells [59-61]. An important component of the pathway involves inflammasomes, which are intracellular multiprotein complexes activated in response to a wide variety of intrinsic and extrinsic danger signals. [62]. To date, the NOD-like receptor (NLR) family pyrin domain containing 3 (NLRP-3) inflammasome has been increasingly recognized to play a major role during aging processes [63]. The inflammasomes are comprised of a sensor molecule, NLRP-3 with a pyrin domain (PYD), and the adaptor protein, apoptosis-associated speck-like protein (ASC), which harbors pro-caspase-1. Upon activation, NLRP-3 interacts with ASC via PYD to form NLRP3-ASC-pro-caspase-1 complex, also known as NLRP-3 inflammasome $[64,65]$. Subsequently, caspase- 1 becomes activated and proceeds to cleave pro-IL-1 $\beta$ and pro-IL-18 into mature IL-1 $\beta$ and IL-18, promoting an inflammatory response [66]. Activated caspase-1 also cleaves gasdermin D (GSDMD) and results in the formation of GSDMD-N terminal domain (GSDMD-N) [67]. The GSDMD-N triggers pyroptosis by translocating into the plasma membrane and inducing membrane pore formation, resulting in cell swelling, release of IL-1 $\beta$ and Il-18, and eventual lysis [68-70].

Accumulating evidence indicates a role for NLRP-3 inflammasomes in CVD and aging, contributing to the chronic activation of inflammatory pathways [63,64]. Experimental manipulation of the innate immune system by over-activating the NLRP-3 inflammasome induces a global age-related inflammatory response in various organs [71]. In this study, NLRP-3 was shown to be the key regulator in age-related increases in IL- $1 \beta$ and caspase- 1 activity in the murine central nervous system (CNS), which was associated with the age-related reduction in cognitive function and motor performance [71]. Genetic ablation of NLRP-3 inflammasome in mice entails metabolic and systemic effects with an improvement in cardiovascular health, such as improved glucose tolerance, the regulation of dyslipidemia and metabolic pathways resulting in enhanced longevity [72]. The improved longevity and health induced by inhibition of NLRP-3 could be partially explained by an increased autophagic response observed in the mice that results in elimination of misfolded proteins in cardiac tissue [72]. Elevated levels of pro-inflammatory cytokines secondary to NLRP-3 inflammasome 
activation, such as IL-1 $\beta$, are often detected in elderly individuals correlating with age-related CVD [38,73]. Indeed, the formation of NLRP-3 inflammasome promotes collagen production and IL-1 $\beta$ activation leading to adverse cardiac remodeling and caspase- 1 mediated cell death $[74,75]$. Mature IL-1 $\beta$ promotes the LV expression of pro-fibrotic tumor growth factor $\beta$ (TGF- $\beta$ ), excessive extracellular matrix (ECM) accumulation and collagen I deposition [76,77]. The subsequent development of myocardial hypertrophy and LV fibrosis are hallmarks of age-related reduced LV elasticity and diastolic dysfunction [78,79].

A consequence of chronic low-grade inflammation is the accumulation of senescent cardiomyocytes resulting in compromised cardiac function, augmented cell death and myocardial dysfunction [39]. In essence, persistent activation of inflammatory pathways, such as NLRP-3 inflammasomes, coupled with the effects of cardiac aging, set the stage for development of HF [40,66,80,81]. Accordingly, in the context of HF, increased levels of NLRP-3 inflammasomes and inflammatory mediators induced by pressure overload in murine hearts have shown to be associated with increased myocardial fibrosis, LV hypertrophy and impaired cardiac function, contributing to progression of the disease. For example, experimental evidence in rodents using Triptolide, a traditional Chinese medicine used for rheumatoid arthritis, demonstrated protective effects by the downregulation of NLRP-3/TGF- $\beta$ pro-fibrotic axis and decreased expression of pro-inflammatory cytokines like IL-1 $\beta$ and IL-18 [82]. Human samples from stressed and injured myocardium demonstrate the presence of elevated levels of NLRP-3 inflammasome-containing immune cells, which potentially contribute to the worsening of HF [74]. While evidence is limited, experimental animal studies suggest inflammasome activation impacts the pathogenesis of HF. Data demonstrating the chronic activation of NLRP-3 is associated with the progressive decline in systolic dysfunction and reduced contractility, which was prevented by blockade of NLRP-3 and IL-1 $\beta$ [83]. Similarly, studies using the NLRP-3 inflammasome inhibitor, MCC950, resulted in slowing the development of HF in both models of myocardial infarction (MI) and pressure overload by suppressing IL-1 $\beta$ release [84]. Together, the current data reflect correlative associations and do not demonstrate causality; however, the continued presence of increased NLRP-3 inflammasome during aging and in HF suggest the importance of this pathway and the need for more research.

\section{Aging Mitochondria Contribute to NLRP-3 Inflammasome Activation}

Given the immense energetic cost of cardiac electrical and mechanical function and the limited capacity for energy storage, the heart mainly relies on mitochondria as a steady energy supply $[44,85]$. Approximately $95 \%$ of cardiac ATP is produced by mitochondria through oxidative phosphorylation. However, the importance of cardiac mitochondrial health and function is now increasingly recognized to reach beyond ATP synthesis [86]. Mitochondria play a central role in a myriad of cellular processes, such as oxidative stress homeostasis, biosynthetic pathways, signaling and programmed cell death [87]. It has long been appreciated that aging is accompanied by a decline in mitochondrial function and quality contributing to a wide variety of age-related diseases, including HF [52,88]. Aged cardiomyocytes show extensive mitochondrial abnormalities, including enlarged structure, loss of cristae, reduction in ATP synthesis, impaired dynamics and increased ROS production $[40,79,86,89]$. Historically, numerous studies have proposed the detrimental alterations in mitochondrial function and structure play a central role in myocardial hypertrophy, fibrosis and consequently transition to HF [90,91]. The role mitochondria have in activating NLRP-3 inflammasomes has led to new concepts for their involvement in aging and age-related diseases and mitochondria-induced inflammasome activation has become central to theories of cardiac aging $[29,92,93]$.

\section{Mitochondria and Oxidative Stress Theory of Aging}

Dysregulated ROS production and impaired antioxidant defense have been implicated in a host of cardiovascular dysfunctions, including cardiac aging and HF [94]. Age-associated oxidative stress has been demonstrated in clinical studies, evidenced by depleted glutathione, 
impaired superoxide dismutase (SOD) and an increase in malondialdehyde levels in elderly individuals [95-97]. Excessive production of ROS triggers numerous adverse effects leading to cell dysfunction, lipid peroxidation and DNA mutagenesis ultimately resulting in irreversible cell damage and death [98]. Conversely, overexpression of antioxidant molecules, including mitochondrial thioredoxin (Trx) and catalase, has been suggested to extend the lifespan in animal models $[99,100]$. The overexpression of human Trx in mice protected murine bone morrow cells from ultraviolet C (UVC)-induced oxidative stress and improved the telomerase activity associated with increased maximum lifespan [99]. Elevated mitochondrial catalase (MCAT) activity in mouse hearts attenuated the severity of age-induced cardiomyopathy and arthrosclerosis reducing oxidative damage to cardiac DNA resulting in a longer median lifespan [100]. The occurrence of increased oxidative stress in aging is thought to be a driver of NLRP-3 inflammasome activation [101]. Several underlying novel pathways regulating age-associated oxidative stress have been elucidated, among which mitochondrial ROS generation is of particular importance in the setting of inflammasomes activation $[38,51,66]$.

Mitochondrial respiratory chain serves as a major source of ROS production where leakage of single electrons are transferred to molecular oxygen forming superoxide anions [102]. Due to the proximity to the electron transport chain, mitochondrial DNA (mtDNA) is highly susceptible to ROS-mediated damage, leading to further mitochondrial dysfunction [103]. The vicious cycle between mitochondrial damage and the further overproduction of ROS causes the dysregulation of various cellular pathways, including inflammation and apoptosis, and eventually resulting in cardiac functional decline $[39,104]$. Interestingly, the leakage of oxidized mtDNA into the cytosol activates the NLRP-3 inflammasome in macrophages exposed to lipopolysaccharide (LPS) and ATP, where depletion of NLRP-3 and ASC attenuated the release of mtDNA [105]. Accordingly, cells lacking mtDNA are unable to secrete IL-1 $\beta$ in response to NLRP-3-activating stimuli, corroborating the active role of mtDNA in NLRP-3 inflammasome activation. More importantly, the oxidized form of mtDNA and not the normal form was shown to bind to and activate NLRP-3 inflammasomes [106]. However, the exact role of mtDNA in NLRP-3 inflammasome activation remains unknown [107]. NLRP-3 inflammasomes require a priming step usually stimulated by inflammatory cytokines, PAMPs or DAMPs, upregulating the expression of inflammasome components. This is followed by the activation step resulting in the inflammasome complex assembly and subsequent activation of caspase-1. A major challenge is understanding the mechanisms involved in the abrupt transition from priming to activation-induced NLRP-3 activators [108]. In a recent study by Karin and colleagues, they reveal the priming and activation of NLRP-3 inflammasome is coupled through the induction of mtDNA synthesis. The newly replicated mtDNA co-precipitates and co-localizes with NLRP-3 inflammasomes in response to NLRP-3 activators. These newly activated mtDNA molecules are also highly sensitive to oxidative stress, which further activates NLRP-3 inflammasomes [107]. This study sheds new light linking mitochondria to both the priming and activating stage of the NLRP-3 inflammasome.

Age-related accumulation of free cholesterol crystals is shown to serve as a pro-inflammatory trigger, activating NLRP-3 inflammasomes and the release of IL-1 $\beta$ [109]. Elevated cellular cholesterol levels impair mitochondrial membrane potential and respiratory function, resulting in increased levels of mtDNA in the cytosol [110,111]. Additionally, impaired mitochondrial structure and the release of mtDNA into the cytosol results in engagement of absent in melanoma 2 (AIM 2) inflammasome in a cholesterol-dependent manner resulting in exaggerated release of IL-1 $\beta$ [111]. Both pharmacological and genetic perturbation of cholesterol trafficking to the endoplasmic reticulum (ER) in macrophages inhibited NLRP-3 inflammasome activation and reduced the secretion of caspase- 1 and IL- $1 \beta$ suggesting a significant role for cholesterol in inflammasome assembly and activation [112].

Based on the oxidative stress hypothesis for aging, both increased ROS levels and a decline in efficiency of the antioxidant system can contribute to the progressive degeneration in cardiac function and structure [113]. Mitochondrial thioredoxin system ( $\operatorname{Trx} 2)$, localized to the mitochondrial matrix, is a free radical scavenger providing the primary defense against mitochondrial ROS. Trx is highly expressed in metabolically active tissues, such as cardiac cells, where it has a major role protecting cells 
against damage [114]. Thioredoxin interacting protein (Txnip) has been identified as a tumor suppressor protein with a primary role of inhibiting the antioxidant activity of Trx via direct interaction [115]. Upon stress conditions, Txnip is shuttled into mitochondria and inhibits Trx-2 leading to increased ROS production and leakage [116]. While Txnip was initially characterized as a key regulator in cellular redox signaling pathways, evidence suggests the function of Txnip goes beyond classical redox biology.

The age-dependent upregulation of Txnip correlates with lower Trx-2 expression levels, which together lead to the accumulation of ROS, increased oxidative stress and the perturbation of cellular redox equilibrium $[114,117,118]$. The increased Txnip expression has been documented in isolated primary T cells from elderly patients ( $>55$ years old) compared to young (20-25 years old) individuals [117]. Further studies in murine models of diabetic nephropathy and from human diabetic patients have revealed increased ROS production results in Txnip mediated activation of the NLRP-3 inflammasome cascade $[119,120]$. Downregulation of Txnip in THP-1 macrophages suppressed caspase- 1 and secretion of IL- $1 \beta$ in response to inflammasome activators, indicating the Txnip/NLRP-3 axis is critical for the inflammatory response. Moreover, intraperitoneal injection of MSU, an inflammasome activator, in Txnip-deficient mice resulted in significantly lower neutrophil influx and IL-1 $\beta$ production [121]. Moreover, inhibiting the NLRP-3/Txnip axis in H9c2 cardiomyocytes suppressed doxorubicin-induced cardiac senescence and cell damage [122]. While our current understanding of the impact altered Txnip levels has toward adverse cardiac effects in aged individuals is limited, evidence suggests it may disrupt the redox status and activate the NLRP-3 inflammasome cascade.

\section{Impaired Mitophagy and Mitochondrial Dynamics in Cardiac Aging and Heart Failure}

Mitochondria are dynamic organelles constantly undergoing fission and fusion events in response to energy demand and cellular stress. The balanced fission and fusion events under basal conditions are responsible for maintaining mitochondrial morphology and metabolism [86]. Key proteins regulating fission include dynamin-related protein 1 (Drp-1) and fission protein 1 (Fis1), while mitofusin 1 and 2 (Mfn-1 and 2) and optic atrophy 1 (OPA1) are involved in mitochondrial fusion in mammals. Altered expression or activation of mitochondrial dynamic proteins have been implicated in the pathogenesis of cardiac diseases [42]. Cardiac specific ablation of Drp-1 gene in mice inhibits mitochondrial fission, resulting in mitochondrial enlargement, increased mitochondrial permeability transition pore (MPTP) opening, apoptosis, and ultimately, lethal dilated cardiomyopathy (DCM) [123]. Interrupting mitochondrial fusion with the deletion of Mfn-1 and Mfn-2 genes in mice also leads to progressive and lethal DCM, primarily due to disrupted mitochondrial structure and respiratory chain function [124]. Evidence suggests that the imbalance between mitochondrial fission and fusion during aging has a role in age-related CVD via compromising mitochondrial integrity $[40,125,126]$. Reduced fission and/or increased fusion have been shown to be associated with elongated, hyper-fused mitochondria in aged tissues [127-129]. For example, changes to the relative expression levels of Mfn-2 and Drp-1 in skeletal muscle of aged mice is associated with more elongated mitochondria [127]. Similarly, mitochondria from aged C. elegans showed significantly enlarged and swollen ultrastructure accompanied by decreased oxygen consumption, increased carbonylated protein and decreased mitochondrial SOD activity [129]. While an elongated morphology is associated with the accumulation of dysfunctional mitochondria in aged tissues, promoting Drp-1 mediated fission in midlife in Drosophila improves mitochondrial respiratory function and structure, prolongs lifespan and delays age-related pathologies [130]. The concomitant interruption of fission and fusion processes can accelerate mitochondrial senescence and result in the accumulation of dysfunctional mitochondria, contributing to the development of HF [104].

HF patients have aberrant mitochondrial dynamics and altered homeostasis [131,132]; as such, understanding the pathophysiology associated with dysfunctional fission/fusion processes in age-related CVD is important. Moreover, considering the importance of inflammasome signaling in the pathogenesis of age-associated HF, deciphering the role of altered mitochondrial dynamics with inflammasome activation is significant. While the mechanistic details are limited, hyper-fused 
mitochondria in mouse bone marrow macrophages, caused by knockdown of Drp-1, are capable of triggering NLRP-3 inflammasome assembly and activation of caspase- 1 and IL-1 $\beta$ [133]. Moreover, the chemical induction of mitochondrial fission by carbonyl cyanide m-chlorophenyl hydrazine-attenuated inflammasome activation in the macrophages [133]. Conversely, ablation of Mfn- 2 in murine macrophages, significantly reduces the activation of IL- $1 \beta$ following RNA virus exposure [134]. Together, while studies on the role of mitochondrial dynamics in HF have been very limited, emerging evidence suggests that the impaired mitochondrial fission/fusion balance are etiologically involved in promoting NLRP-3 inflammasome activation and contribute to the disease progression.

Mitophagy is a highly selective autophagic process of the degradation of damaged mitochondria necessary for maintaining cellular homeostasis, and is closely associated with mitochondrial dynamics [135]. Overtime, or as a consequence of stress, when mitochondria sustain damage too severe to overcome, they undergo mitophagic removal [136]. Diminished mitophagy results in cellular accumulation of dysfunctional mitochondria, reducing overall quality, which may contribute to the aging process [126]. There are multiple proposed mechanisms for the removal of damaged mitochondria, such as the serine/threonine kinase PTEN-inducible kinase 1 (PINK1)/E3 ubiquitin ligase (Parkin) pathway [137]. Upon mitochondrial damage and membrane depolarization, PINK1 accumulates on the outer membrane of mitochondria and mediates phosphorylation and subsequent activation of Parkin leading to ubiquitination of mitochondrial proteins, including Mfn-2 [135]. The recruitment of mitochondrial proteins promotes the interaction of damaged mitochondria to LC3-positive phagosomes for degradation in lysosomes. Any impairment of these processes can lead to mitochondrial dysfunction and cell death $[138,139]$.

There is growing evidence from animal models and clinical data suggesting that dysfunctional mitophagy results in the accumulation of dysfunctional mitochondria and augments myocardial cell death and necrosis, thereby accelerating the progress toward cardiomyopathy and HF [139-142]. Both the expression and activity of PINK- 1 were significantly reduced in mice with heart failure 14 days following transverse aortic constriction (TAC). Increasing cardiac mitophagy was observed in PINK-1 protected mice in a chronic TAC-induced HF model resulting in improved mitochondrial function [142]. Furthermore, studies in C. elegans and Drosophila demonstrate enhancing mitophagy promotes a protective mechanism against mitochondrial stress and results in the extension of lifespan [143-145]. Defective mitophagy characterized by the accumulation of damaged mitochondria was observed in accelerated aging in Werner syndrome (WS) in both human fibroblasts and C. elegans. Interestingly, treatment with Urolithin A, a mitophagy specific inducer, improved pharyngeal pumping of the worms and extended their lifespan [143]. Accordingly, despite not fully understood, impaired mitophagy has been critically linked to aberrant inflammatory responses, including NLRP-3 inflammasome activation [146]. Parkin deficiency enhances mitochondrial membrane potential loss, augments mitochondrial ROS production and mtDNA release leading to elevated activation of IL-1 $\beta$ and caspase-1, in response to NLRP-3 agonists [147]. Conversely, upregulated Parkin expression and enhanced mitophagy inhibits NLRP-3 inflammasome assembly and activation of downstream signaling molecules promoting cell survival [148].

Although many of these studies lack the mechanistic explanation, it can be hypothesized that insufficient mitophagy leads to the accumulation of dysfunctional mitochondria, excessive production of ROS and oxidized mtDNA, which in turn, triggers inflammasome activation $[144,149,150]$. Together, the current data suggest an important intersection between mitochondrial dynamics, mitophagy and inflammasome activation in the progression and development of age-associated CVD.

\section{Macrophages and Chronic Inflammation}

Aging is an inevitable part of life, posing the largest risk factor for all myocardial diseases [151]. Higher levels of fibrosis, cardiomyocyte loss and cellular hypertrophy are morphological hallmarks of aged hearts contributing to worsened outcomes of almost all cardiac pathologies, including HF [152]. 
Accumulating evidence suggests aging is associated with a general remodeling of the immune system leading to an "autoimmune" sterile inflammatory response that can contribute to cardiac structural changes [153,154]. Multiple mechanisms have been proposed to explain how chronic low-grade inflammation impacts the process of cardiac aging, ranging from mitochondrial dysfunction and metabolic disorders to dysregulation of immune cells $[155,156]$.

Macrophages are integral components of the innate immune system and are critical in the homeostatic maintenance of the myocardium under steady-state conditions and after tissue injury [157]. In addition to their classical roles in host defense, macrophages are involved in cardiac remodeling, healing and clearing senescent cells contributing to tissue homeostasis [158]. The predominant belief was tissue macrophages were simply derived from circulating monocytes, however, it is now well-established that cardiac resident macrophages are derived from embryonic hematopoietic progenitors, independent from infiltrating monocytes [159]. Despite the existence of a heterogeneous macrophage population in the mammalian heart, macrophages are broadly subdivided into pro-inflammatory M1 and anti-inflammatory M2 phenotypes [160]. Although both M1 and M2 macrophages can be divided into various subcategories, tissue macrophages are traditionally categorized into anti-inflammatory M2 population and recruited infiltrating monocyte-derived macrophages are generally categorized as a M1 inflammatory group [161]. While direct evidence of the role of macrophages in inflammaging and age-associated diseases is scarce, a shift in macrophage populations in aged hearts in favor of M1 phenotype suggests involvement in age-related cardiac deterioration [162]. Using genetic fate mapping and parabiotic approaches, Molawi et al. indicated that the number of resident macrophages declines in aged hearts and infiltrating monocytes progressively contribute to the cardiac macrophage population [163]. In addition to the decreased ratio of M2/M1 macrophages, the self-renewal capacity of cardiac macrophages is dampened with physiological aging, which may contribute to the vulnerability and worsened prognosis of an aged heart following injury $[164,165]$. The quantification of the total number of cardiac macrophages by staining the proliferation antigen phospho-histone 3 (PH3) showed a decline in the number of cardiac macrophages in 30-week-old mice compared to their 4-week-old counterparts. Interestingly, cardiac macrophages from 15-25-week-old mice demonstrated upregulation of pro-fibrotic genes, such as matrix metallopeptidase 9 (MMP-9), TGF- $\beta 1$ and fibroblast growth factor receptor 1 (FGFR-1) [165]. Accordingly, an age-associated progressive loss of M2 macrophages is linked to a prolonged inflammatory status accelerating cardiac aging [166].

Aging is associated with increased accumulation and circulation of DAMPs that are hypothesized to play a major role in the age-associated low-grade inflammation [167]. Accumulating evidence suggests macrophages are primary responders in age-related sterile inflammation and persistent activation of macrophages by age-associated DAMPs is one of the main mechanisms in inflammaging and tissue dysfunction [168]. Mechanistically, mitochondrial dysfunction and increased oxidative stress occurring with age and M1 polarization may result in hyper-activation of NLRP-3 inflammasome and IL-1 $\beta$ release contributing to age-related pathologies $[169,170]$. Telomere attrition is a hallmark of the aging process which can be reversed by the action of telomerase enzyme. Telomerase-deficient macrophages showed abnormal mitochondrial function and ultrastructure accompanied with increased mROS production resulting in activation of NLRP-3 inflammasome. Further relating the impaired mitochondria to inflammasome activation, treatment with mito-TEMPO, a specific scavenger of mROS, significantly attenuated the enhanced activation of caspase- 1 and IL- $\beta$ in telomerase-deficient macrophages [169]. Although the endogenous mechanisms linking macrophages to aging and longevity is unknown, inhibiting the macrophage-derived inflammatory cytokine cascade successfully improved lifespan in drosophila [171]. Evidence suggests the downregulation of NLRP-3 inflammasomes in macrophages maintains immune homeostasis in aged-tissues leading to pro-longevity effects [172]. Together, the data suggest M1 macrophage associated inflammasomes drive adverse age-associated low-grade inflammation while M2 macrophages provide anti-inflammatory benefits. 


\section{N-3 and N-6 Polyunsaturated Fatty Acids (PUFAs)}

Long-chain polyunsaturated fatty acids (PUFA) are essential fatty acids obtained from dietary sources which are required for cellular organelles, such as phospholipid membranes, and serve as precursors to numerous bioactive lipid mediators [173]. Linoleic acid (LA) is the primary source of $\mathrm{N}-6$ PUFA, which is converted to arachidonic acid (AA), while $\alpha$-linolenic acid (ALA) is considered the main N-3 PUFA precursor [174]. Inside the body, the conversion of ALA and LA to their corresponding downstream metabolites happens through multiple elongation and desaturation steps [175]. ALA can be converted into eicosapentaenoic acid (EPA) which can be further metabolized to yield docosahexaenoic acid (DHA); however, the conversion is very limited in humans [176]. Since the N-3 and N-6 PUFAs compete for the same metabolic pathways, the dietary N-3:N-6 PUFA ratio plays a critical role in normal tissue function and development [174]. A typical western diet provides higher levels of LA resulting in predominant generation of LA-derived eicosanoids, which results in an unbalanced ratio correlating with the etiology of many diseases, including CVD [175,177].

Emerging evidence demonstrates the epoxy, hydroxyl and diol metabolites derived from N-3 and N-6 PUFA metabolism have important properties. The metabolism of N-3 and N-6 PUFA occurs primarily through three enzymatic systems, cyclooxygenases (COX), lipoxygenases (LOX) and cytochrome P450 (CYP) enzymes, into a plethora of bioactive metabolites. Various members of the CYP superfamily are capable of metabolizing N-3 and N-6 PUFAs into bioactive lipid mediators (Figure 1).

\section{CYP-DERIVED EPOXYLIPIDS}

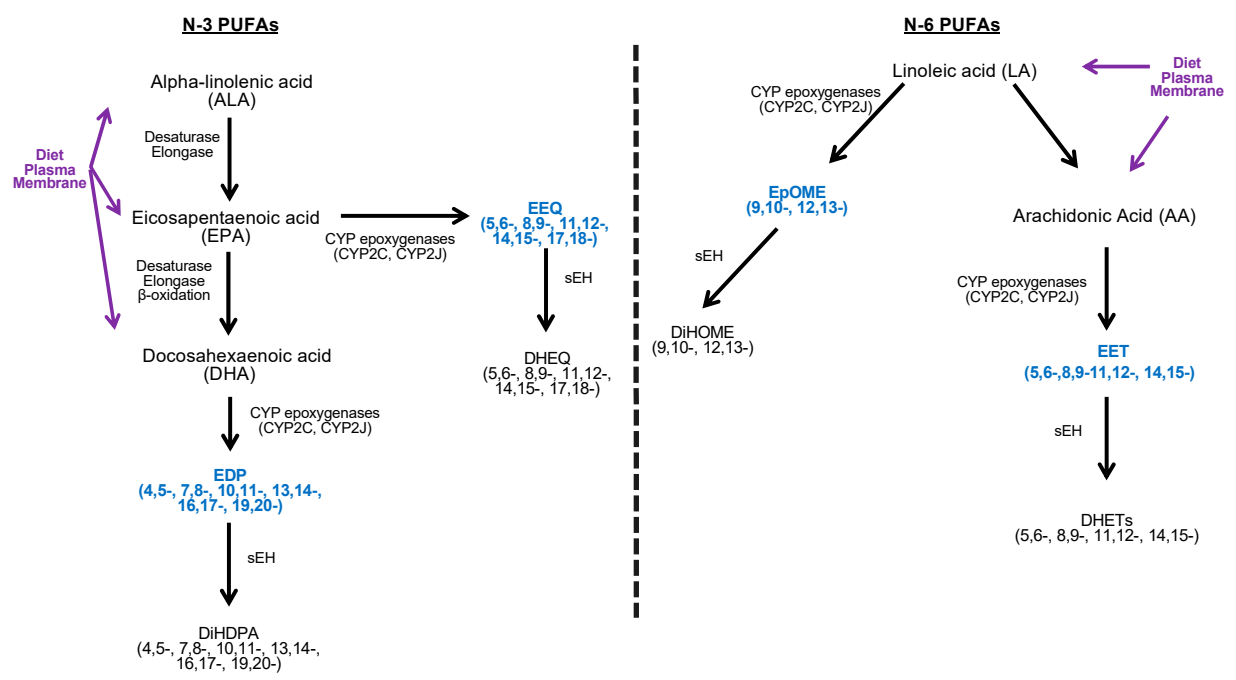

Figure 1. Overview of metabolic pathway of CYP-derived epoxylipids. LA, AA, ALA, EPA, and DHA are essential dietary fatty acids and are found in membrane phospholipids. AA: arachidonic acid; ALA: $\alpha$-linolenic acid; CYP: cytochrome P450. DiHOME: dihydroxyoctadecenoic acid; DHA: docosahexaenoic acid; DiHDPA: dihydroxydocosapentaneoic acid; DHEQ: dihydroxyeicosatetraenoic acid; DHET: dihydroxyeicosatrienoic acid; EET: epoxyeicosatrienoic acid; EDP: epoxydocosapentaenoic acid; EEQ: epoxyeicosatetraenoic acid; EpOME: epoxyoctadecamonoenic acid; LA: linoleic acid; PUFA: poly unsaturated fatty acid, sEH: soluble epoxide hydrolase.

In the cardiovascular system, CYP2J and CYP2C isozymes are major epoxygenases responsible for converting AA, a N-6 PUFA, into four regioisomeric epoxyyeicosatrienoic acids (5,6-, 8,9-, 11,12-, and 14,15-EET) by olefin epoxidation [178,179]. As well, converting the N-3 PUFAs, EPA into 5 regioisomeric epoxyeicosatetraenoic acids $(5,6-, 8,9-, 11,12-, 14,15-, 17,18-\mathrm{EEQ})$ and DHA into 6 regioisomeric epoxydocosapentaenoic acids $(4,5-, 7,8-, 10,11-, 13,14-, 16,17-, 19,20-E D P)$ [180]. In the heart, EETs act as the key lipid mediators, regulating cellular mechanisms, including mitochondrial 
quality control, apoptosis, and inflammatory pathways [181-183]. Although little is known about the exact mechanisms of the cardioprotective effects of N-3 PUFAs, recent evidence demonstrates that CYP-derived epoxy metabolites possess anti-inflammatory and cardioprotective effects $[184,185]$. Most N-3 and N-6 epoxylipids, including EETs, EDP and EEQ, have a short half-life and are rapidly metabolized to their corresponding less active diol metabolites by the enzyme soluble epoxide hydrolase (sEH) $[186,187]$.

Over the past decade, experimental studies have demonstrated EETs mediate a myriad of cellular and metabolic pathways, which are cardioprotective toward several pathologies including HF [187-190]. For instance, Cao et al. reported that using (S)-2-(11-(nonyloxy) undec-8(Z)-enamido) succinic acid (NUDSA), an EET agonist, in a murine model of myocardial infarction (MI) is associated with improved systolic dysfunction, decreased myocardial fibrosis and limited remodeling in post-infarcted HF [191]. Similarly, the administration of an orally active EET mimetic in hypertensive rats exposed to ischemia-reperfusion-induced HF, reduced cardiac associated mortality, provided better cardiac function, reduced pulmonary edema, reduced myocardial fibrosis and decreased macrophage infiltration. Moreover, EET mimetic treatment increased the activity of hem-oxygenase 1 (HO-1) following ischemia-reperfusion injury and attenuated the progression of HF [192]. In a murine model of HF, treatment with sEH inhibitor, adamantan-3-(5-(2-(2-ethylethoxy) ethoxy) pentyl) urea (AEPU) to limit epoxylipid metabolism, prevented pressure-overload-induced cardiac hypertrophy and decreased susceptibility to ventricular arrhythmias. Furthermore, treatment with AEPU decreased the translocation of NF- $\mathrm{kB}$ from the cytosol into the nucleus in mouse neonatal cardiomyocytes subjected to Angiotensin II (Ang II)-induced hypertension and hypertrophy [193]. Moreover, transgenic mice with cardiomyocyte overexpression of CYP2J2 subjected to pressure-overload or long-term infusion of isoproterenol demonstrated reduced hypertrophy and arrhythmogenic events [194]. Evidence suggest that EETs play a major cardioprotective role in HF by decreasing secretion of pro-fibrotic factors leading to reduced remodeling [195]. Mice with cardiac overexpression of CYP2J2 showed improved cardiac function, decreased myocardial hypertrophy and fibrosis resulting in amelioration of cardiac remodeling. Further defining the cardioprotective role of CYP2J2, neonatal cardiomyocytes from mice with cardiac overexpression of CYP2J2 showed decreased level of cardiac remodeling proteins, such as collagen type I, and TGF- $\beta$ in response to Ang II compared to their WT counterparts [195]. Although the exact mechanism of the cardioprotective effects of EETs remains unknown, these studies established evidence that EETs have promising therapeutic effects for improving cardiac outcomes in HF.

The evidence suggesting N-3 PUFAs have cardioprotective effects against pathological hypertrophy and HF is controversial [187]. Experimental animal studies suggest there are beneficial effects of N-3 PUFAs toward CVD. For example, in a mouse model of HF, increased myocardial EPA and DHA levels following dietary-supplementation-attenuated LV chamber dilation against pressure-overload-induced cardiomyopathy providing a proof-of-concept. Moreover, following TAC, mice fed with EPA and DHA showed improved mitochondrial function documented by preservation of citrate synthase and medium chain acyl-CoA dehydrogenase (MCAD) activity [196]. However, differences in the clinical literature from several prospective observational studies and large-scale clinical trials testing the protective effects of N-3 PUFAs have had mixed results [197]. The "GISSI-HF" trial demonstrated N-3 PUFA supplementation was associated with reduced HF-related hospital admissions and mortality in patients with reduced ejection fraction [198]. Conversely, a randomized double-blind trial by the "Alpha-Omega Trial Group" concluded that there was no significant benefit for N-3 PUFA toward cardiovascular events post-MI [199]. These differences may be partially attributed to study design, such as the inclusion of populations with a high baseline intake of N-3 PUFA and differing doses of EPA and DHA, yet no studies to date investigate the role of the CYP-derived epoxy metabolites.

Both preclinical and clinical studies have furnished a wealth of evidence in support of cardioprotective effects of epoxy fatty acids [187,190,196,200]. However, their short half-life limits their therapeutic use and clinical application requiring new strategies to improve 
their pharmacokinetics $[187,201]$. The gene encoding sEH, Ephx2, is the primary enzyme metabolizing PUFA epoxides resulting in the formation of respective diol metabolites via the addition of a water molecule [182,183]. Novel pharmacological approaches that selectively inhibit sEH have evolved as clinical tools in various cardiovascular diseases, including hypertension, cerebral ischemia, cardiac ischemia, cardiac hypertrophy, myocardial infarction and atherosclerosis [202-207]. Pharmacological sEH inhibition is demonstrated to improve both LV diastolic and systolic function and attenuate myocardial remodeling in established HF $[188,208,209]$. Treatment with cis-4-[4-(3-adamantan-1-yl-ureido) cyclohexyloxy] benzoic acid (c-AUCB)-attenuated increased systolic and diastolic LV cavity diameter following ischemia/reperfusion injury in rats. Interestingly, the combined administration of EET mimetic and c-AUCB amplified the cardioprotective effects of the single therapy and significantly decreased the MI-induced chamber dilation accompanied with improved systolic function [188]. Chronic inhibition of sEH substantially attenuated lung congestion and albuminuria parallel to preserved cardiac function and structure, acknowledging sEH as a therapeutic target for the treatment of HF associated with chronic kidney disease [210,211]. Despite considerable research on the role of $\mathrm{sEH}$, significant gaps remain at many levels in the understanding of mechanisms involved in beneficial effects of sEH inhibition in the setting of cardiovascular diseases.

CYP-dependent oxidation of LA results in the production of epoxyoctadecanoic acids (EpOME), which are rapidly metabolized by $\mathrm{sEH}$ to their corresponding diol metabolites, dihydroxyoctadecanoic acids (DiHOME) [187]. Evidence from animal and in vitro studies has suggested DiHOMEs are potent cytotoxic metabolites [212]. Increased levels of cardiac DiHOMEs are thought to be associated with deteriorated myocardial electrical activity, altered ion channel kinetics, depressed LV function and impaired mitochondrial respiration [213-216]. The cardiotoxic effects of DiHOMEs remained evident when cardiac specific over-expression of CYP2J2 failed to improve cardiac functional recovery following ischemia reperfusion, attributed to age-related accumulation of DiHOMEs in the heart [217]. Indeed, the deleterious myocardial effects of DiHOMEs counter the cardioprotective effects of increased epoxylipids [218]. These data suggest that the cardioprotection of sEH inhibition could be mediated, at least in part, by inhibiting the production of cardiotoxic DiHOMEs. However, further investigation into cardiac effects of DiHOMEs is warranted.

\section{Anti-Inflammatory Effects of N-3 and N-6 PUFA-Derived Epoxylipids}

Several experimental, clinical and epidemiological studies reported that the cardioprotective effects of the epoxylipids derived from N-3 and N-6 PUFAs against various cardiac pathologies are attributed to their immunomodulatory properties. The anti-inflammatory properties of N-3 and N-6 PUFAs as well as their corresponding epoxylipids have been demonstrated in both cardiac and extra-cardiac tissues $[219,220]$. For example, EETs ameliorated inflammatory responses in human endothelial cells subjected to TNF- $\alpha$-stimulated inflammation, by decreasing the expression of cytokine-induced adhesion molecule, vascular cell adhesion molecule-1 (VCAM-1) and preventing leucocyte adhesion attributed to inhibition of nuclear transcription factor-kappa B (NF-kB) activity. Supportive investigations determining the effects of EETs in vascular inflammation demonstrated intra-arterial perfusion of 11,12-EET decreased endothelial VCAM-1 expression and prevented the adhesion of mononuclear cells in mice following injection of TNF- $\alpha$ [219]. Moreover, the increase in EET levels associated with the cardiac specific overexpression of CYP2J2-attenuated atrial fibrosis and inflammatory responses in a mouse model of atrial fibrillation induced by constriction of the abdominal aorta [221]. Treatment with EET analogs limited myocardial fibrosis and macrophage infiltration, decelerating the progression of MI-induced HF in rats subjected to ligation of left anterior descending (LAD) coronary artery [192]. While the exact mechanisms remain unknown, current data provides compelling evidence that anti-inflammatory properties of EETs play a major role in their cardioprotective effects. 
Emerging evidence indicates a beneficial immunomodulatory role for N-3 PUFA involves limiting mitochondrial dysfunction and subsequent NLRP3 inflammasome activation in hearts subjected to ischemia-reperfusion injury. Hearts perfused with DHA or 19,20-EDP demonstrated preserved mitochondrial quality, as evidenced by the reduced mitochondria translocation of Drp-1, Txnip, preserved OPA-1 expression and better mitochondrial function [204,222]. In another study, TNF- $\alpha$-stimulated primary human retinal microvascular endothelial cells treated with exogenous EETs or EDPs in combination with a sEH inhibitor, 12-(3-adamantane-1-yl-ureido)-dodecanoic acid (AUDA) resulted in inhibited leucocyte adherence and attenuated retinal vascular inflammation. AUDA prevented the metabolism of both endogenous and exogenous EET and EDP and attenuated TNF- $\alpha$-induced VCAM-1 expression [223]. Similarly, when obese mice subjected to high-fat diet were treated with EPA and DHA, a robust anti-inflammatory response was observed involving attenuation of NF-kB activation and TNF- $\alpha$ pro-inflammatory cascade. Interestingly, in the same study, genetic deletion of G-protein coupled receptor 120 (GPR-120) completely abrogated the effects of EPA and DHA supplementation on insulin sensitivity and glucose infusion rate in mice subjected to a high-fat diet [224]. In a randomized, double blind cross-over controlled study, DHA and EPA supplementation in trained endurance athletes for ten weeks, significantly lowered values of muscle inflammatory markers, including IL-6 and IL-1 $\beta$, paralleled with reduced muscle damage indices [225]. In another study on a murine model of hypertension treated with angiotensin (Ang)-II, co-administration of sEH inhibitor with EPA and DHA effectively decreased Ang-II-dependent hypertension and attenuated release of renal inflammatory markers, such as MCP-1 and prostaglandins [226]. The emerging evidence is suggesting that N-3 PUFAs and their metabolites have important anti-inflammatory properties suggesting novel therapeutic approaches in CVD.

There is a growing body of evidence demonstrating both genetic and pharmacological inhibition of sEH abrogate the uncontrolled sterile inflammation in different settings [187,227,228]. For instance, Yang et al. showed the sEH inhibitor, trans-4-\{4-[3-(4-trifluoromethoxyphenyl)-ureido] -cyclohexyloxy\}-benzoic acid (t-TUCB), increased concentrations of the anti-inflammatory EETs and simultaneously decreased the concentrations of type $2 \mathrm{~T}$ helper cells (Th2), cytokines (IL-4, IL-5) and chemokines as well as total cell and eosinophil numbers in the lung lavage of a murine ovalbumin (OVA) model of asthma [229]. The sEH inhibitor 12-(3-adamantan-1-yl-ureido)-dodecanoic acid butyl ester (AUDA-BE) and 1-adamantan-3-(5-(2-(2-ethylethoxy)ethoxy)pentyl)urea (compound 950), increased EET levels, reduced the concentration of the pro-inflammatory cytokines, such as TNF- $\alpha$, IL-6 and MCP-5, accelerated inflammatory resolution and prevented mortality in a mouse model of septic shock [230]. The inhibition of sEH significantly ameliorated inflammatory responses, attenuated neutrophil infiltration and decreased the expression of pro-inflammatory cytokines, such as TNF- $\alpha$ and IFN- $\gamma$ in a mouse model of inflammatory bowel disease treated with piroxicam [231]. In a rat model of ischemic stroke induced by middle cerebral artery occlusion, the administration of a pharmacological inhibitor of sEH decreased the mRNA level of IL-1 $\beta$ and IL- 6 and modulated microglia polarization toward decreased M1 and increased M2, resulting in reduced infarct size and improved behavior outcomes [232]. Furthermore, incubation of primary murine macrophages subjected to LPS with novel dual COX-2/sEH inhibitor-attenuated ROS production, reduced the level of caspase- 1 and IL- $1 \beta$ and inhibited NLRP3 activation [233]. Although the balance of evidence suggests substantial benefits of sEH inhibitors with respect to CVDs, the exact cardioprotective mechanism of sEH inhibition remains controversial and an area of active investigation.

LA is metabolized to EpOMEs by CYP epoxygenases and further to DiHOMEs by sEH [187]. DiHOMEs are characterized as pro-inflammatory mediators in pain contributing to the pathophysiology of the disease [234]. Further, 12,13-DiHOMEs promote monocyte infiltration and expression of pro-inflammatory cytokines resulting in inflammatory immunologic responses [235]. Increased epoxide hydrolase expression and 12,13-DiHOME concentrations are associated with an increased probability of developing childhood allergies associated with inflammatory properties [236]. There is limited information regarding the adverse impact of DiHOMEs toward cardiac function and 
aging. However, evidence suggests the myocardial accumulation of 12, 13-DiHOME correlates with LPS-induced cytotoxicity and a decline in mitochondrial function and cell survival [212]. The 12,13-DiHOME-augmented release of ROS and mitochondrial dysfunction in hearts exposed to ischemia-reperfusion is associated with diminished myocardial functional recovery [213]. Together, sEH inhibition results in increased levels of epoxylipids while decreasing DiHOME production potentially altering cardiac inflammatory responses.

\section{Mitochondria: Effects of N-3 and N-6 PUFA-Derived Epoxylipids}

Mitochondria play a fundamental role in cardiac aging by regulating a plethora of age-associated cardiac changes, particularly the age-induced pro-inflammatory status [237]. Therefore, targeting mitochondrial dysfunction in the aging myocardium is an unmet need holding significant promise for age-related cardiac diseases. Although the exact mechanisms of how epoxylipids regulate cardiac function are not fully understood, accumulating data suggest mitochondria-targeted effects are an important component of their cardioprotective properties [203,212,238]. Numerous in vivo and ex vivo studies demonstrate $\mathrm{sEH}$ inhibition or treatment with epoxylipids improve LV functional recovery in murine hearts following ischemia-reperfusion injury protecting mitochondrial function and ultrastructure [181,206,225,238-241]. Previously, we reported hearts perfused with UA-8 (13-(3-propylureido) tridec-8-enoic acid) a synthetic dual-action compound possessing EET mimetic and sEH inhibitory properties, improved post-ischemic contractile function and reduced infarct size following ischemia-reperfusion injury. These cardioprotective effects were attributed to the ability of UA-8 to prevent the collapse of mitochondrial function and limit the loss of mitochondrial membrane potential, resulting in preserved heart function [242]. The inhibition of endogenous EET production by a selective epoxygenase inhibitor, MS-PPOH, resulted in the disruption of mitochondrial ATP generation, increased ROS production, mitochondrial depolarization and mitochondrial fragmentation in cultured neonatal hippocampal astrocytes [243]. Both treatment with exogenous EET and CYP2J2 overexpression suppressed ROS production and increased expression of catalase, as well as cytosolic and mitochondrial superoxide dismutase leading to improved viability in human pulmonary artery endothelial cells subjected to anoxia/reoxygenation [244]. The administration of an EET agonist effectively ameliorated obesity-induced cardiomyopathy by improving mitochondrial function and energy metabolism in cardiac tissues leading to enhanced tolerance to glucose challenge, associated with increased cardiac expression of PGC-1 $\alpha$, a key regulator in mitochondrial biogenesis [245]. Moreover, in the same study, EET-treated mice showed increased level of manganese superoxide dismutase (MnSOD) and Mfn- 2 in adipose tissues, contributing to balancing the mitochondrial function and redox status [245]. Ablation of the sEH gene in mice decreased the degradation of EETs leading to a significant increase in Mfn-1, HO-1 and the cytochrome c oxidase subunit I (COX-I) level in adipose tissue compared to WT control mice, further revealing a key role for EETs in regulating mitochondrial integrity and function [246]. The sEH deletion also maintained both mitochondrial function and ATP generation in isolated murine cardiac fibers subjected to LAD in both young and aged mice, contributing to sustained systolic and diastolic function. Moreover, both young and aged sEH null mice had preserved mitochondrial ultrastructure following myocardial infarction (MI) characterized by improved cristae density and organization [206].

Although the effects of N-3 PUFAs on mitochondria are less extensively studied and characterized, they are increasingly recognized to protect the heart by preserving mitochondrial function $[247,248]$. A DHA-rich diet significantly improved the ROS-induced MPTP opening in interfibrillar mitochondria and decreased mitochondrial membrane viscosity associated with a modest attenuation of LV dysfunction in rats with HF [249]. Both EPA and DHA exhibited an up-regulatory effect on the expression of Mfn-2 resulting in a significant recovery of mitochondrial network architecture and morphology accompanied by increased ATP production in steatotic HepG2 cells incubated with oleate and palmitate [250]. The anti-apoptotic and pro-survival effects of N-3 PUFAs by shifting the cell death pathway toward survival have been also reported $[183,244]$. DHA attenuated apoptosis, evidenced by 
increased Bcl-2 and decreased Bax and cleaved caspase- 3 via upregulating OPA- 1 and ameliorating mitochondrial fragmentation following subarachnoid hemorrhage in rats subjected to ligation of the carotid artery [251].

Sirtuin 3 (Sirt-3) is a nicotinamide adenine dinucleotide (NAD)-dependent histone deacetylase found predominately in mitochondria which has been identified as a key mediator in age-related cardiovascular physiology, regulating mitochondrial oxidative stress via deacetylating MnSOD [252,253]. Cardiomyocytes lacking Sirt-3 show age-dependent mitochondrial swelling and accelerated signs of cardiac aging, including myocardial hypertrophy and accumulated fibrotic tissue [254]. Interestingly, while the cardiac expression of sEH is significantly increased in cardiac aging, the genetic deletion of sEH attenuated the age-related decrease in Sirt-3 activity in female mice [255]. The effect was associated with higher levels of active mitochondrial MnSOD resulting in better overall cardiac function, suggesting the preservation of mitochondrial integrity in aged mice [255]. This data fosters an important body of research on the underlying mechanisms involved in the effects of epoxylipids on mitochondrial redox apparatus in cardiac aging and age-related pathogenesis.

The dysregulation of mitochondrial dynamics and mitophagy found in aged hearts is associated with an accumulation of damaged mitochondria and subsequent activation of inflammatory responses [126]. The suppression of sEH demonstrated to increase expression of Mfn- 1 associated with improved cardiac mitochondrial function and biogenesis, increased ATP production, ameliorated cardiac inflammation and consequently protected the heart from metabolic syndrome [256]. EETs also maintained the increased expression of Mfn-2 and MnSOD in obesity-induced cardiomyopathy shedding more light on their role in maintaining mitochondrial homeostasis [245]. While the mechanisms remain unknown, there appears to be a role for epoxylipids in regulating mitochondrial function in aged hearts.

\section{Sex Differences and N-3 and N-6 Polyunsaturated Fatty Acids}

Biological aging is associated with slowly progressive deterioration in cardiac function and structure, predisposing elderly adults to cardiovascular diseases [257]. There is growing evidence that significant sex differences exist in presentation, progression and treatment responses as individuals age, resulting in different clinical outcomes between men and women and highlighting the importance and necessity of considering sex differences in aging studies [258-260]. Males present greater LV mass and chamber dimensions with increased susceptibility toward developing eccentric LV remodeling, systolic dysfunction and DCM at younger ages [261]. However, upon aging, increased myocardial wall thickness has been reported to occur in females, which may be accompanied by concentric LV chamber remodeling and diastolic dysfunction, predisposing females to HF [258,260]. Furthermore, there are several cardiovascular risk factors exclusively experienced by women, including menopause, early menarche, preeclampsia, and pregnancy [262]. The higher incidence of CVD in men compared to women prior to menopause suggests sex hormones play key role in development [263]. However, emerging research has indicated sex hormones alone are insufficient to fully explain the variations in cardiac outcomes between men and women [264]. Interestingly, the data pertaining to biological sex-differences show distinct disparities in male and female mitochondrial function and morphology [265]. Female mitochondria are more differentiated with increased cristae density and protein content resulting in lower levels of free radical production and higher efficiency [265-267]. In view of the fact that mitochondria are strongly associated with age-related cardiac differences, comparable mitochondrial sex-differences appear to be a promising theory to explain sex-specific differences in cardiac aging. Sexual dimorphism has been documented in protein expression and regulation of sEH activity in both cardiac and extra-cardiac tissues [255,268-270]. While sEH inhibition did not have discernable effects on female mouse systolic blood pressure (SBP), genetic deletion of sEH efficiently normalized SBP in male mice [270]. Sexual disparity in regulating sEH activity becomes more pronounced in aged tissues, as aging is associated with a significant increase in SEH in male 
animals. This raises new questions on the mechanisms associated with sex-specific responses to sEH-based interventions $[255,268]$.

\section{Conclusions}

Our understanding of the progression of cardiac aging is largely exclusive to a collection of intriguing yet unconnected data sets bridging the age-associated inflammasome activation and age-related CVD. Identifying novel approaches to modulate aged-induced immune responses will provide insights into the development of effective therapeutics with limited adverse effects. In the current review, we briefly discussed the immunomodulatory properties of PUFA-based epoxy fatty acids and sEH inhibitors. Several mechanisms contribute to the immunomodulatory effects of epoxylipids, from which maintaining mitochondrial structure and function is of great importance in the platform of aging and age-related HF. Taken together, while our understanding of the role of epoxylipids in modulating the immune system remains limited, several findings have highlighted their diverse cardioprotective activities and provided ideas toward developing novel therapeutic approaches (Figure 2).

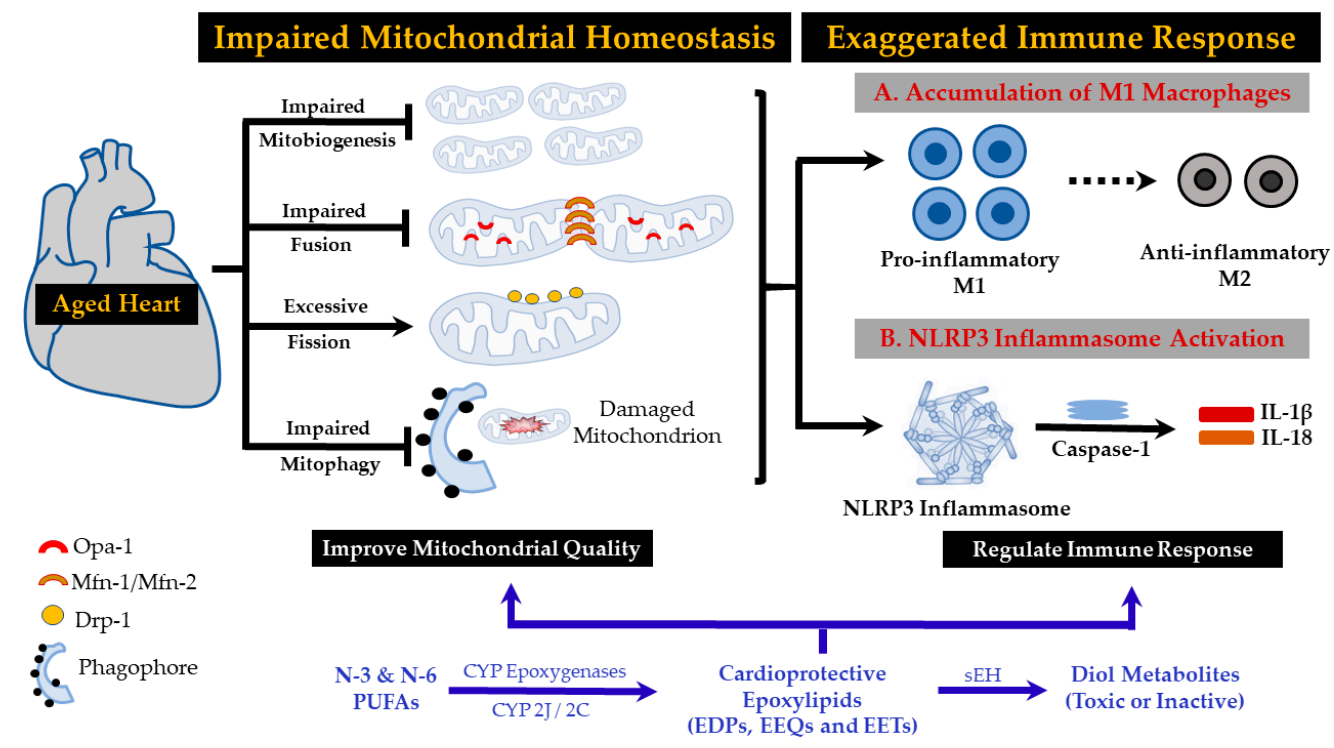

Figure 2. Schematic diagram of the potential modulatory effects of cytochrome P450 (CYP)-derived epoxylipids against cardiac inflammaging. Cardiac senescence is an intrinsic process accompanied by a general decline in mitochondrial function and impaired mitochondrial homeostasis, as evidenced by reduced mitochondrial biogenesis, dysregulated fusion, exaggerated fission and suppressed mitophagy. These changes result in the accumulation of damaged mitochondria, which triggers an innate immune response characterized by cardiac infiltration of pro-inflammatory M1 macrophages and assembly of the NLRP3 inflammasomes. N-3 and N-6 PUFAs can be metabolized by CYP isoenzymes to their corresponding epoxylipids, which (i) maintain/improve mitochondrial integrity and function and (ii) attenuate NLRP3 inflammasome activation, suggesting a proof-of-concept for beneficial effects against inflammaging and age-related cardiac pathologies. DRP-1: dynamin-related protein 1, EET: epoxyeicosatrienoic acid, EDP: epoxydocosapentaenoic acid, EEQ: epoxyeicosatetraenoic acid, IL: interleukin, MFN: mitofusin, NLRP3: NOD-like receptor family, pyrin domain containing 3, OPA-1: optic atrophy 1, PUFA: poly unsaturated fatty acid, sEH: soluble epoxide hydrolase.

Author Contributions: H.K.-B. was responsible for designing the outline of the review, researching the data and writing the manuscript. A.M.D. provided substantial contribution to design and content of the review. D.K.S. was responsible for screening the eligible studies and extracting the data. J.M.S. was the PI and involved in the design of the review, reviewing and editing the manuscript. All authors have read and agreed to the published version of the manuscript. 
Funding: This study was supported by a grant from the Natural Sciences and Engineering Research Council (NSERC) of Canada to J.M.S. H.K.-B is funded by generous supporters of the Lois Hole Hospital for Women through the Women and Children's Health Research Institute. A.M.D. is supported by an Alberta Innovates Graduate Studentship in Health Innovation.

Conflicts of Interest: The authors declare no conflict of interest in the preparation of this work.

\section{References}

1. Dai, D.-F.; Chiao, Y.-A.; Wessells, R.J.; Bodmer, R.; Szeto, H.H.; Rabinovitch, P.S. Cardiac Aging. In Handbook of the Biology of Aging; Elsevier: Amsterdam, The Netherlands, 2016; pp. 459-494.

2. Hung, C.-L.; Gonçalves, A.; Shah, A.M.; Cheng, S.; Kitzman, D.; Solomon, S.D. Age-and sex-related influences on left ventricular mechanics in elderly individuals free of prevalent heart failure: The ARIC study (Atherosclerosis Risk in Communities). Circ. Cardiovasc. Imaging 2017, 10, e004510. [CrossRef]

3. Steenman, M.; Lande, G. Cardiac aging and heart disease in humans. Biophys. Rev. 2017, 9, $131-137$. [CrossRef] [PubMed]

4. Lye, M.; Donnellan, C. Heart disease in the elderly. Heart 2000, 84, 560-566. [CrossRef] [PubMed]

5. $\quad$ Rodgers, J.L.; Jones, J.; Bolleddu, S.I.; Vanthenapalli, S.; Rodgers, L.E.; Shah, K.; Karia, K.; Panguluri, S.K. Cardiovascular risks associated with gender and aging. J. Cardiovasc. Dev. Dis. 2019, 6, 19. [CrossRef] [PubMed]

6. Dai, D.-F.; Chen, T.; Johnson, S.C.; Szeto, H.; Rabinovitch, P.S. Cardiac aging: From molecular mechanisms to significance in human health and disease. Antioxid. Redox Signal. 2012, 16, 1492-1526. [CrossRef]

7. Díez-Villanueva, P.; Alfonso, F. Heart failure in the elderly. J. Geriatr. Cardiol. 2016, 13, 115.

8. Hilfiker-Kleiner, D.; Landmesser, U.L.F.; Drexler, H. Molecular mechanisms in heart failure: Focus on cardiac hypertrophy, inflammation, angiogenesis, and apoptosis. J. Am. Coll. Cardiol. 2006, 48, A56-A66. [CrossRef]

9. Ezekowitz, J.A.; O’Meara, E.; McDonald, M.A.; Abrams, H.; Chan, M.; Ducharme, A.; Giannetti, N.; Grzeslo, A.; Hamilton, P.G.; Heckman, G.A. 2017 Comprehensive update of the Canadian Cardiovascular Society guidelines for the management of heart failure. Can. J. Cardiol. 2017, 33, 1342-1433. [CrossRef]

10. Yancy, C.W.; Jessup, M.; Bozkurt, B.; Butler, J.; Casey, D.E., Jr.; Drazner, M.H.; Fonarow, G.C.; Geraci, S.A.; Horwich, T.; Januzzi, J.L. 2013 ACCF/AHA guideline for the management of heart failure: A report of the American College of Cardiology Foundation/American Heart Association Task Force on Practice Guidelines. Circulation 2013, 128, e240. [CrossRef]

11. Owan, T.E.; Hodge, D.O.; Herges, R.M.; Jacobsen, S.J.; Roger, V.L.; Redfield, M.M. Trends in prevalence and outcome of heart failure with preserved ejection fraction. N. Engl. J. Med. 2006, 355, 251-259. [CrossRef]

12. Satomura, H.; Wada, H.; Sakakura, K.; Kubo, N.; Ikeda, N.; Sugawara, Y.; Ako, J.; Momomura, S.-I. Congestive heart failure in the elderly: Comparison between reduced ejection fraction and preserved ejection fraction. J. Cardiol. 2012, 59, 215-219. [CrossRef]

13. Tsao, C.W.; Lyass, A.; Enserro, D.; Larson, M.G.; Ho, J.E.; Kizer, J.R.; Gottdiener, J.S.; Psaty, B.M.; Vasan, R.S. Temporal trends in the incidence of and mortality associated with heart failure with preserved and reduced ejection fraction. JACC Heart Fail. 2018, 6, 678-685. [CrossRef] [PubMed]

14. Sharma, K.; Kass, D.A. Heart failure with preserved ejection fraction: Mechanisms, clinical features, and therapies. Circ. Res. 2014, 115, 79-96. [CrossRef] [PubMed]

15. Borlaug, B.A. Mechanisms of exercise intolerance in heart failure with preserved ejection fraction. Circ. J. 2014, 78, 20-32. [CrossRef] [PubMed]

16. Lam, C.S.; Roger, V.L.; Rodeheffer, R.J.; Bursi, F.; Borlaug, B.A.; Ommen, S.R.; Kass, D.A.; Redfield, M.M. Cardiac structure and ventricular-vascular function in persons with heart failure and preserved ejection fraction from Olmsted County, Minnesota. Circulation 2007, 115, 1982-1990. [CrossRef] [PubMed]

17. Zile, M.R.; Baicu, C.F.; Gaasch, W.H. Diastolic heart failure-abnormalities in active relaxation and passive stiffness of the left ventricle. N. Engl. J. Med. 2004, 350, 1953-1959. [CrossRef] [PubMed]

18. Borlaug, B.A.; Lam, C.S.; Roger, V.L.; Rodeheffer, R.J.; Redfield, M.M. Contractility and ventricular systolic stiffening in hypertensive heart disease insights into the pathogenesis of heart failure with preserved ejection fraction. J. Am. Coll Cardiol. 2009, 54, 410-418. [CrossRef]

19. Shah, A.M.; Pfeffer, M.A. The many faces of heart failure with preserved ejection fraction. Nat. Rev. Cardiol. 2012, 9, 555-556. [CrossRef] 
20. Paulus, W.J.; Tschope, C. A novel paradigm for heart failure with preserved ejection fraction: Comorbidities drive myocardial dysfunction and remodeling through coronary microvascular endothelial inflammation. J. Am. Coll Cardiol. 2013, 62, 263-271. [CrossRef]

21. Danielsen, R.; Thorgeirsson, G.; Einarsson,H.; Ólafsson, Ö.; Aspelund, T.; Harris, T.B.; Launer, L.; Gudnason, V. Prevalence of heart failure in the elderly and future projections: The AGES-Reykjavík study. Scand. Cardiovasc. J. 2017, 51, 183-189. [CrossRef]

22. Duque, E.R.; Briasoulis, A.; Alvarez, P.A. Heart failure with preserved ejection fraction in the elderly: Pathophysiology, diagnostic and therapeutic approach. J. Geriatr. Cardiol. JGC 2019, 16, 421. [PubMed]

23. Lazzarini, V.; Mentz, R.J.; Fiuzat, M.; Metra, M.; O'Connor, C.M. Heart failure in elderly patients: Distinctive features and unresolved issues. Eur. J. Heart Fail. 2013, 15, 717-723. [CrossRef]

24. Upadhya, B.; Kitzman, D.W. Heart failure with preserved ejection fraction in older adults. Heart Fail. Clin. 2017, 13, 485-502. [CrossRef] [PubMed]

25. Pfeffer, M.A.; Shah, A.M.; Borlaug, B.A. Heart failure with preserved ejection fraction in perspective. Circ. Res. 2019, 124, 1598-1617. [CrossRef] [PubMed]

26. Valero-Muñoz, M.; Backman, W.; Sam, F. Murine Models of Heart Failure With Preserved Ejection Fraction. JACC Basic Transl. Sci. 2019, 2, 770-789. [CrossRef] [PubMed]

27. Marco Metra, J.R.T. Heart failure. Lancet 2017, 390, 1981-1995. [CrossRef]

28. Yoon, S.; Eom, G.H. Heart failure with preserved ejection fraction: Present status and future directions. Exp. Mol. Med. 2019, 51,1-9. [CrossRef]

29. Bellumkonda, L.; Tyrrell, D.; Hummel, S.L.; Goldstein, D.R. Pathophysiology of heart failure and frailty: A common inflammatory origin? Aging Cell 2017, 16, 444-450. [CrossRef] [PubMed]

30. Ferrara, N.; Komici, K.; Corbi, G.; Pagano, G.; Furgi, G.; Rengo, C.; Femminella, G.D.; Leosco, D.; Bonaduce, D. $\beta$-adrenergic receptor responsiveness in aging heart and clinical implications. Front. Physiol. 2014, 4, 396. [CrossRef]

31. Shioi, T.; Inuzuka, Y. Aging as a substrate of heart failure. J. Cardiol. 2012, 60, 423-428. [CrossRef]

32. Metra, M.; Cotter, G.; El-Khorazaty, J.; Davison, B.A.; Milo, O.; Carubelli, V.; Bourge, R.C.; Cleland, J.G.; Jondeau, G.; Krum, H. Acute heart failure in the elderly: Differences in clinical characteristics, outcomes, and prognostic factors in the VERITAS Study. J. Card. Fail. 2015, 21, 179-188. [CrossRef] [PubMed]

33. Metra, M.; Mentz, R.J.; Chiswell, K.; Bloomfield, D.M.; Cleland, J.G.F.; Cotter, G.; Davison, B.A.; Dittrich, H.C.; Fiuzat, M.; Givertz, M.M. Acute heart failure in elderly patients: Worse outcomes and differential utility of standard prognostic variables. Insights from the PROTECT trial. Eur. J. Heart Fail. 2015, 17, 109-118. [CrossRef] [PubMed]

34. Kernaghan, K. Serving seniors: Innovation and public sector service delivery. Innov. J. 2015, $20,2$.

35. Seals, D.R.; Brunt, V.E.; Rossman, M.J. Keynote lecture: Strategies for optimal cardiovascular aging. Am. J. Physiol. Heart Circ. Physiol. 2018, 315, H183-H188. [CrossRef] [PubMed]

36. Franceschi, C.; Garagnani, P.; Parini, P.; Giuliani, C.; Santoro, A. Inflammaging: A new immune-metabolic viewpoint for age-related diseases. Nat. Rev. Endocrinol. 2018, 14, 576-590. [CrossRef]

37. Cannata, A.; Marcon, G.; Cimmino, G.; Camparini, L.; Ciucci, G.; Sinagra, G.; Loffredo, F.S. Role of circulating factors in cardiac aging. J. Thorac. Dis. 2017, 9, S17. [CrossRef]

38. Franceschi, C.; Campisi, J. Chronic inflammation (inflammaging) and its potential contribution to age-associated diseases. J. Gerontol. Ser. A Biomed. Sci. Med. Sci. 2014, 69, S4-S9. [CrossRef]

39. Li, H.; Hastings, M.H.; Rhee, J.; Trager, L.E.; Roh, J.D.; Rosenzweig, A. Targeting Age-Related Pathways in Heart Failure. Circ. Res. 2020, 126, 533-551. [CrossRef]

40. Miyamoto, S. Autophagy and cardiac aging. Cell Death Differ. 2019, 26, 653-664. [CrossRef]

41. Marín-García, J.; Pi, Y.; Goldenthal, M.J. Mitochondrial-nuclear cross-talk in the aging and failing heart. Cardiovasc. Drugs Ther. 2006, 20, 477-491. [CrossRef] [PubMed]

42. Marín-García, J.; Akhmedov, A.T. Mitochondrial dynamics and cell death in heart failure. Heart Fail. Rev. 2016, 21, 123-136. [CrossRef] [PubMed]

43. Brown, D.A.; Perry, J.B.; Allen, M.E.; Sabbah, H.N.; Stauffer, B.L.; Shaikh, S.R.; Cleland, J.G.F.; Colucci, W.S.; Butler, J.; Voors, A.A. Expert consensus document: Mitochondrial function as a therapeutic target in heart failure. Nat. Rev. Cardiol. 2017, 14, 238-250. [CrossRef] [PubMed]

44. Huss, J.M.; Kelly, D.P. Mitochondrial energy metabolism in heart failure: A question of balance. J. Clin. Investig. 2005, 115, 547-555. [CrossRef] 
45. Ventura-Clapier, R.; Garnier, A.; Veksler, V.; Joubert, F. Bioenergetics of the failing heart. Biochim. Et. Biophys. Acta Mol. Cell Res. 2011, 1813, 1360-1372. [CrossRef]

46. Hausenloy, D.J.; Ruiz-Meana, M. Not Just the Powerhouse of the Cell: Emerging Roles for Mitochondria in the Heart; Oxford University Press: Oxford, UK, 2010.

47. Marin-Garcia, J.; Goldenthal, M.J.; Moe, G.W. Mitochondrial pathology in cardiac failure. Cardiovasc. Res. 2001, 49, 17-26. [CrossRef]

48. Kornfeld, O.S.; Hwang, S.; Disatnik, M.-H.; Chen, C.-H.; Qvit, N.; Mochly-Rosen, D. Mitochondrial reactive oxygen species at the heart of the matter: New therapeutic approaches for cardiovascular diseases. Circ. Res. 2015, 116, 1783-1799. [CrossRef]

49. Chen, Y.; Zhou, Z.; Min, W. Mitochondria, oxidative stress and innate immunity. Front. Physiol. 2018, 9, 1487. [CrossRef]

50. Fang, C.; Wei, X.; Wei, Y. Mitochondrial DNA in the regulation of innate immune responses. Protein Cell 2016, 7, 11-16. [CrossRef]

51. West, A.P. Mitochondrial dysfunction as a trigger of innate immune responses and inflammation. Toxicology 2017, 391, 54-63. [CrossRef]

52. Salminen, A.; Ojala, J.; Kaarniranta, K.; Kauppinen, A. Mitochondrial dysfunction and oxidative stress activate inflammasomes: Impact on the aging process and age-related diseases. Cell. Mol. Life Sci. 2012, 69, 2999-3013. [CrossRef]

53. Gasteiger, G.; D’Osualdo, A.; Schubert, D.A.; Weber, A.; Bruscia, E.M.; Hartl, D. Cellular innate immunity: An old game with new players. J. Innate Immun. 2017, 9, 111-125. [CrossRef]

54. Janeway, C.A., Jr.; Medzhitov, R. Innate immune recognition. Annu. Rev. Immunol. 2002, 20, $197-216$. [CrossRef]

55. Pérez-Vázquez, D.; Contreras-Castillo, E.; Licona-Limón, P. Innate immune memory, the missing piece of the immunological response. Tip Rev. Espec. En Cienc. Químico-Biológicas 2019, 21, 112-123.

56. Amarante-Mendes, G.P.; Adjemian, S.; Branco, L.M.; Zanetti, L.C.; Weinlich, R.; Bortoluci, K.R. Pattern recognition receptors and the host cell death molecular machinery. Front. Immunol. 2018, 9, 2379. [CrossRef]

57. Roh, J.S.; Sohn, D.H. Damage-associated molecular patterns in inflammatory diseases. Immune Netw. 2018, 18, e27. [CrossRef]

58. Tang, D.; Kang, R.; Coyne, C.B.; Zeh, H.J.; Lotze, M.T. PAMP s and DAMP s: Signal 0s that spur autophagy and immunity. Immunol. Rev. 2012, 249, 158-175. [CrossRef]

59. Iwasaki, A.; Medzhitov, R. Regulation of adaptive immunity by the innate immune system. Science 2010, 327, 291-295. [CrossRef]

60. Jeannin, P.; Jaillon, S.; Delneste, Y. Pattern recognition receptors in the immune response against dying cells. Curr. Opin. Immunol. 2008, 20, 530-537. [CrossRef]

61. Lee, M.S.; Kim, Y.-J. Signaling pathways downstream of pattern-recognition receptors and their cross talk. Annu. Rev. Biochem. 2007, 76, 447-480. [CrossRef]

62. Kelley, N.; Jeltema, D.; Duan, Y.; He, Y. The NLRP3 inflammasome: An overview of mechanisms of activation and regulation. Int. J. Mol. Sci. 2019, 20, 3328. [CrossRef]

63. Latz, E.; Duewell, P. NLRP3 Inflammasome Activation in Inflammaging. In Seminars in Immunology; Academic Press: Cambridge, MA, USA, 2018; pp. 61-73. [CrossRef]

64. He, Y.; Hara, H.; Núñez, G. Mechanism and regulation of NLRP3 inflammasome activation. Trends Biochem. Sci. 2016, 41, 1012-1021. [CrossRef]

65. Zahid, A.; Li, B.; Kombe, J.K.; Jin, T.; Tao, J. Pharmacological Inhibitors of the NLRP3 Inflammasome. Front. Immunol. 2019, 10, 2538. [CrossRef]

66. Jo, E.-K.; Kim, J.K.; Shin, D.-M.; Sasakawa, C. Molecular mechanisms regulating NLRP3 inflammasome activation. Cell. Mol. Immunol. 2016, 13, 148-159. [CrossRef]

67. Sollberger, G.; Choidas, A.; Burn, G.L.; Habenberger, P.; Di Lucrezia, R.; Kordes, S.; Menninger, S.; Eickhoff, J.; Nussbaumer, P.; Klebl, B. Gasdermin D plays a vital role in the generation of neutrophil extracellular traps. Sci. Immunol. 2018, 3, eaar6689. [CrossRef] [PubMed]

68. Wang, Y.-Y.; Liu, X.-L.; Zhao, R. Induction of pyroptosis and its implications in cancer management. Front. Oncol. 2019, 9, 971. [CrossRef]

69. Zeng, C.; Wang, R.; Tan, H. Role of pyroptosis in cardiovascular diseases and its therapeutic implications. Int. J. Biol. Sci. 2019, 15, 1345. [CrossRef] 
70. Abbate, A.; Toldo, S.; Marchetti, C.; Kron, J.; Van Tassell, B.W.; Dinarello, C.A. Interleukin-1 and the inflammasome as therapeutic targets in cardiovascular disease. Circ. Res. 2020, 126, 1260-1280. [CrossRef]

71. Youm, Y.-H.; Grant, R.W.; McCabe, L.R.; Albarado, D.C.; Nguyen, K.Y.; Ravussin, A.; Pistell, P.; Newman, S.; Carter, R.; Laque, A. Canonical Nlrp3 inflammasome links systemic low-grade inflammation to functional decline in aging. Cell Metab. 2013, 18, 519-532. [CrossRef] [PubMed]

72. Marín-Aguilar, F.; Lechuga-Vieco, A.V.; Alcocer-Gómez, E.; Castejón-Vega, B.; Lucas, J.; Garrido, C.; Peralta-Garcia, A.; Pérez-Pulido, A.J.; Varela-López, A.; Quiles, J.L. NLRP3 inflammasome suppression improves longevity and prevents cardiac aging in male mice. Aging Cell 2020, 19, e13050. [CrossRef]

73. Ferrucci, L.; Fabbri, E. Inflammageing: Chronic inflammation in ageing, cardiovascular disease, and frailty. Nat. Rev. Cardiol. 2018, 15, 505-522. [CrossRef]

74. Butts, B.; Gary, R.A.; Dunbar, S.B.; Butler, J. The importance of NLRP3 inflammasome in heart failure. J. Card. Fail. 2015, 21, 586-593. [CrossRef] [PubMed]

75. Li, X.; Geng, J.; Zhao, J.; Ni, Q.; Zhao, C.; Zheng, Y.; Wang, L.; Chen, X. Trimethylamine N-oxide exacerbates cardiac fibrosis via activating the NLRP3 inflammasome. Front. Physiol. 2019, 10, 866. [CrossRef] [PubMed]

76. Pinar, A.A.; Scott, T.E.; Huuskes, B.M.; Cáceres, F.E.T.; Kemp-Harper, B.K.; Samuel, C.S. Targeting the NLRP3 inflammasome to treat cardiovascular fibrosis. Pharm. Ther. 2020, 209, 107511. [CrossRef]

77. Van Hout, G.P.J.; Bosch, L.; Ellenbroek, G.H.J.M.; De Haan, J.J.; Van Solinge, W.W.; Cooper, M.A.; Arslan, F.; De Jager, S.C.A.; Robertson, A.A.B.; Pasterkamp, G. The selective NLRP3-inflammasome inhibitor MCC950 reduces infarct size and preserves cardiac function in a pig model of myocardial infarction. Eur. Heart J. 2017, 38, 828-836. [CrossRef]

78. Cañadas-Lozano, D.; Marín-Aguilar, F.; Castejón-Vega, B.; Ryffel, B.; Navarro-Pando, J.M.; Ruiz-Cabello, J.; Alcocer-Gómez, E.; Bullón, P.; Cordero, M.D. Blockade of the NLRP3 inflammasome improves metabolic health and lifespan in obese mice. GeroScience 2020, 42, 715-725. [CrossRef]

79. Quarles, E.K.; Dai, D.-F.; Tocchi, A.; Basisty, N.; Gitari, L.; Rabinovitch, P.S. Quality control systems in cardiac aging. Ageing Res. Rev. 2015, 23, 101-115. [CrossRef]

80. Chen, W.; Frangogiannis, N.G. The role of inflammatory and fibrogenic pathways in heart failure associated with aging. Heart Fail. Rev. 2010, 15, 415-422. [CrossRef]

81. Loffredo, F.S.; Nikolova, A.P.; Pancoast, J.R.; Lee, R.T. Heart failure with preserved ejection fraction: Molecular pathways of the aging myocardium. Circ. Res. 2014, 115, 97-107. [CrossRef]

82. Li, R.; Lu, K.; Wang, Y.; Chen, M.; Zhang, F.; Shen, H.; Yao, D.; Gong, K.; Zhang, Z. Triptolide attenuates pressure overload-induced myocardial remodeling in mice via the inhibition of NLRP3 inflammasome expression. Biochem. Biophys. Res. Commun. 2017, 485, 69-75. [CrossRef]

83. Bracey, N.A.; Beck, P.L.; Muruve, D.A.; Hirota, S.A.; Guo, J.; Jabagi, H.; Wright, J.R., Jr.; MacDonald, J.A.; Lees-Miller, J.P.; Roach, D. The Nlrp3 inflammasome promotes myocardial dysfunction in structural cardiomyopathy through interleukin-1 $\beta$. Exp. Physiol. 2013, 98, 462-472. [CrossRef]

84. Sano, S.; Oshima, K.; Wang, Y.; MacLauchlan, S.; Katanasaka, Y.; Sano, M.; Zuriaga, M.A.; Yoshiyama, M.; Goukassian, D.; Cooper, M.A. Tet2-mediated clonal hematopoiesis accelerates heart failure through a mechanism involving the IL-1ß/NLRP3 inflammasome. J. Am. Coll. Cardiol. 2018, 71, 875-886. [CrossRef] [PubMed]

85. Rosca, M.G.; Hoppel, C.L. Mitochondria in heart failure. Cardiovasc. Res. 2010, 88, 40-50. [CrossRef]

86. Zhao, Q.; Sun, Q.; Zhou, L.; Liu, K.; Jiao, K. Complex Regulation of Mitochondrial Function During Cardiac Development. J. Am. Heart Assoc. 2019, 8, e012731. [CrossRef] [PubMed]

87. Di Lisa, F.; Bernardi, P. Mitochondrial function and myocardial aging. A critical analysis of the role of permeability transition. Cardiovasc. Res. 2005, 66, 222-232. [CrossRef] [PubMed]

88. Haas, R.H. Mitochondrial Dysfunction in Aging and Diseases of Aging; Multidisciplinary Digital Publishing Institute: Basel, Switzerland, 2019.

89. Fried, L.P.; McNamara, R.L.; Burke, G.L.; Siscovick, D.S. Heart health in older adults. Import of heart disease and opportunities for maintaining cardiac health. West. J. Med. 1997, 167, 240. [PubMed]

90. Lin, R.; Kerkelä, R. Regulatory Mechanisms of Mitochondrial Function and Cardiac Aging. Int. J. Mol. Sci. 2020, 21, 1359. [CrossRef]

91. Tocchi, A.; Quarles, E.K.; Basisty, N.; Gitari, L.; Rabinovitch, P.S. Mitochondrial dysfunction in cardiac aging. Biochim. Et Biophys. Acta Bioenerg. 2015, 1847, 1424-1433. [CrossRef] 
92. Linton, P.-J.; Gurney, M.; Sengstock, D.; Mentzer, R.M., Jr.; Gottlieb, R.A. This old heart: Cardiac aging and autophagy. J. Mol. Cell. Cardiol. 2015, 83, 44-54. [CrossRef]

93. Volt, H.; García, J.A.; Doerrier, C.; Díaz-Casado, M.E.; Guerra-Librero, A.; López, L.C.; Escames, G.; Tresguerres, J.A.; Acuña-Castroviejo, D. Same molecule but different expression: Aging and sepsis trigger NLRP3 inflammasome activation, a target of melatonin. J. Pineal Res. 2016, 60, 193-205. [CrossRef]

94. Liguori, I.; Russo, G.; Curcio, F.; Bulli, G.; Aran, L.; Della-Morte, D.; Gargiulo, G.; Testa, G.; Cacciatore, F.; Bonaduce, D. Oxidative stress, aging, and diseases. Clin. Interv. Aging 2018, 13, 757. [CrossRef]

95. Andriollo-Sanchez, M.; Hininger-Favier, I.; Meunier, N.; Venneria, E.; O'Connor, J.M.; Maiani, G.; Coudray, C.; Roussel, A.M. Age-related oxidative stress and antioxidant parameters in middle-aged and older European subjects: The ZENITH study. Eur. J. Clin. Nutr. 2005, 59, S58-S62. [CrossRef]

96. Naregal, G.V.; Devaranavadagi, B.B.; Patil, S.G.; Aski, B.S. Elevation of oxidative stress and decline in endogenous antioxidant defense in elderly individuals with hypertension. J. Clin. Diagn. Res. 2017, 11, BC09. [CrossRef]

97. Nuttall, S.L.; Dunne, F.; Kendall, M.J.; Martin, U. Age-independent oxidative stress in elderly patients with non-insulin-dependent diabetes mellitus. QJM 1999, 92, 33-38. [CrossRef] [PubMed]

98. Rababa'h, A.M.; Guillory, A.N.; Mustafa, R.; Hijjawi, T. Oxidative stress and cardiac remodeling: An updated edge. Curr. Cardiol. Rev. 2018, 14, 53-59. [CrossRef] [PubMed]

99. Mitsui, A.; Hamuro, J.; Nakamura, H.; Kondo, N.; Hirabayashi, Y.; Ishizaki-Koizumi, S.; Hirakawa, T.; Inoue, T.; Yodoi, J. Overexpression of human thioredoxin in transgenic mice controls oxidative stress and life span. Antioxid. Redox Signal. 2002, 4, 693-696. [CrossRef] [PubMed]

100. Schriner, S.E.; Linford, N.J.; Martin, G.M.; Treuting, P.; Ogburn, C.E.; Emond, M.; Coskun, P.E.; Ladiges, W.; Wolf, N.; Van Remmen, H. Extension of murine life span by overexpression of catalase targeted to mitochondria. Science 2005, 308, 1909-1911. [CrossRef] [PubMed]

101. Bullone, M.; Lavoie, J.-P. The contribution of oxidative stress and inflamm-aging in human and equine asthma. Int. J. Mol. Sci. 2017, 18, 2612. [CrossRef] [PubMed]

102. Sawyer, D.B.; Colucci, W.S. Mitochondrial Oxidative Stress in Heart Failure: "Oxygen Wastage" Revisited; Am Heart Assoc: Dallas, TX, USA, 2000.

103. Han, Y.; Chen, J.Z. Oxidative stress induces mitochondrial DNA damage and cytotoxicity through independent mechanisms in human cancer cells. Biomed. Res. Int. 2013, 2013. [CrossRef]

104. Dai, D.-F.; Rabinovitch, P.S. Cardiac aging in mice and humans: The role of mitochondrial oxidative stress. Trends Cardiovasc. Med. 2009, 19, 213-220. [CrossRef] [PubMed]

105. Nakahira, K.; Haspel, J.A.; Rathinam, V.A.K.; Lee, S.-J.; Dolinay, T.; Lam, H.C.; Englert, J.A.; Rabinovitch, M.; Cernadas, M.; Kim, H.P. Autophagy proteins regulate innate immune responses by inhibiting the release of mitochondrial DNA mediated by the NALP3 inflammasome. Nat. Immunol. 2011, 12, 222. [CrossRef]

106. Shimada, K.; Crother, T.R.; Karlin, J.; Dagvadorj, J.; Chiba, N.; Chen, S.; Ramanujan, V.K.; Wolf, A.J.; Vergnes, L.; Ojcius, D.M. Oxidized mitochondrial DNA activates the NLRP3 inflammasome during apoptosis. Immunity 2012, 36, 401-414. [CrossRef] [PubMed]

107. Zhong, Z.; Liang, S.; Sanchez-Lopez, E.; He, F.; Shalapour, S.; Lin, X.-j.; Wong, J.; Ding, S.; Seki, E.; Schnabl, B. New mitochondrial DNA synthesis enables NLRP3 inflammasome activation. Nature 2018, 560, 198-203. [CrossRef] [PubMed]

108. Groslambert, M.; Py, B.F. Spotlight on the NLRP3 inflammasome pathway. J. Inflamm. Res. 2018, 11, 359. [CrossRef]

109. Youm, Y.-H.; Kanneganti, T.-D.; Vandanmagsar, B.; Zhu, X.; Ravussin, A.; Adijiang, A.; Owen, J.S.; Thomas, M.J.; Francis, J.; Parks, J.S. The Nlrp3 inflammasome promotes age-related thymic demise and immunosenescence. Cell Rep. 2012, 1, 56-68. [CrossRef]

110. Hamilton, C.; Anand, P.K. Right place, right time: Localisation and assembly of the NLRP3 inflammasome. F1000Research. 2019, 8, 676. [CrossRef]

111. Dang, E.V.; McDonald, J.G.; Russell, D.W.; Cyster, J.G. Oxysterol restraint of cholesterol synthesis prevents AIM2 inflammasome activation. Cell 2017, 171, 1057-1071. [CrossRef] [PubMed]

112. De la Roche, M.; Hamilton, C.; Mortensen, R.; Jeyaprakash, A.A.; Ghosh, S.; Anand, P.K. Trafficking of cholesterol to the ER is required for NLRP3 inflammasome activation. J. Cell Biol. 2018, 217, 3560-3576. [CrossRef] 
113. Tan, B.L.; Norhaizan, M.E.; Liew, W.-P.-P.; Sulaiman Rahman, H. Antioxidant and oxidative stress: A mutual interplay in age-related diseases. Front. Pharm. 2018, 9, 1162. [CrossRef] [PubMed]

114. Sun, H.Y.; Hu, Y.J.; Zhao, X.Y.; Zhong, Y.; Zeng, L.L.; Chen, X.B.; Yuan, J.; Wu, J.; Sun, Y.; Kong, W. Age-related changes in mitochondrial antioxidant enzyme Trx2 and TXNIP-Trx2-ASK 1 signal pathways in the auditory cortex of a mimetic aging rat model: Changes to Trx2 in the auditory cortex. FEBS J. 2015, 282, 2758-2774. [CrossRef]

115. Huy, H.; Song, H.Y.; Kim, M.J.; Kim, W.S.; Kim, D.O.; Byun, J.E.; Lee, J.; Park, Y.J.; Kim, T.D.; Yoon, S.R. TXNIP regulates AKT-mediated cellular senescence by direct interaction under glucose-mediated metabolic stress. Aging Cell 2018, 17, e12836. [CrossRef]

116. Lane, T.; Flam, B.; Lockey, R.; Kolliputi, N. TXNIP shuttling: Missing link between oxidative stress and inflammasome activation. Front. Physiol. 2013, 4, 50. [CrossRef]

117. Oberacker, T.; Bajorat, J.; Ziola, S.; Schroeder, A.; Röth, D.; Kastl, L.; Edgar, B.A.; Wagner, W.; Gülow, K.; Krammer, P.H. Enhanced expression of thioredoxin-interacting-protein regulates oxidative DNA damage and aging. FEBS Lett. 2018, 592, 2297-2307. [CrossRef]

118. Sverdlov, A.L.; Chan, W.P.A.; Procter, N.E.K.; Chirkov, Y.Y.; Ngo, D.T.M.; Horowitz, J.D. Reciprocal regulation of NO signaling and TXNIP expression in humans: Impact of aging and ramipril therapy. Int. J. Cardiol. 2013, 168, 4624-4630. [CrossRef] [PubMed]

119. Han, Y.; Xu, X.; Tang, C.; Gao, P.; Chen, X.; Xiong, X.; Yang, M.; Yang, S.; Zhu, X.; Yuan, S. Reactive oxygen species promote tubular injury in diabetic nephropathy: The role of the mitochondrial ros-txnip-nlrp3 biological axis. Redox Biol. 2018, 16, 32-46. [CrossRef]

120. Kong, X.; Lu, A.-L.; Yao, X.-M.; Hua, Q.; Li, X.-Y.; Qin, L.; Zhang, H.-M.; Meng, G.-X.; Su, Q. Activation of NLRP3 inflammasome by advanced glycation end products promotes pancreatic islet damage. Oxidative Med. Cell. Longev. 2017, 2017. [CrossRef]

121. Zhou, R.; Tardivel, A.; Thorens, B.; Choi, I.; Tschopp, J. Thioredoxin-interacting protein links oxidative stress to inflammasome activation. Nat. Immunol. 2010, 11, 136. [CrossRef] [PubMed]

122. Huang, P.P.; Fu, J.; Liu, L.H.; Wu, K.F.; Liu, H.X.; Qi, B.M.; Liu, Y.; Qi, B.L. Honokiol antagonizes doxorubicin-induced cardiomyocyte senescence by inhibiting TXNIP-mediated NLRP3 inflammasome activation. Int. J. Mol. Med. 2020, 45, 186-194. [CrossRef] [PubMed]

123. Song, M.; Mihara, K.; Chen, Y.; Scorrano, L.; Dorn Ii, G.W. Mitochondrial fission and fusion factors reciprocally orchestrate mitophagic culling in mouse hearts and cultured fibroblasts. Cell Metab. 2015, 21, 273-286. [CrossRef]

124. Chen, Y.; Liu, Y.; Dorn, G.W. Mitochondrial fusion is essential for organelle function and cardiac homeostasis. Circ. Res. 2011, 109, 1327-1331. [CrossRef]

125. Seo, A.Y.; Joseph, A.-M.; Dutta, D.; Hwang, J.C.Y.; Aris, J.P.; Leeuwenburgh, C. New insights into the role of mitochondria in aging: Mitochondrial dynamics and more. J. Cell Sci. 2010, 123, 2533-2542. [CrossRef]

126. Wu, N.N.; Zhang, Y.; Ren, J. Mitophagy, Mitochondrial Dynamics, and Homeostasis in Cardiovascular Aging. Oxidative Med. Cell. Longev. 2019. [CrossRef] [PubMed]

127. Leduc-Gaudet, J.-P.; Picard, M.; Pelletier, F.S.-J.; Sgarioto, N.; Auger, M.-J.; Vallée, J.; Robitaille, R.; St-Pierre, D.H.; Gouspillou, G. Mitochondrial morphology is altered in atrophied skeletal muscle of aged mice. Oncotarget 2015, 6, 17923. [CrossRef] [PubMed]

128. Rana, A.; Rera, M.; Walker, D.W. Parkin overexpression during aging reduces proteotoxicity, alters mitochondrial dynamics, and extends lifespan. Proc. Natl. Acad. Sci. USA 2013, 110, 8638-8643. [CrossRef] [PubMed]

129. Yasuda, K.; Ishii, T.; Suda, H.; Akatsuka, A.; Hartman, P.S.; Goto, S.; Miyazawa, M.; Ishii, N. Age-related changes of mitochondrial structure and function in Caenorhabditis elegans. Mech. Ageing Dev. 2006, 127, 763-770. [CrossRef]

130. Rana, A.; Oliveira, M.P.; Khamoui, A.V.; Aparicio, R.; Rera, M.; Rossiter, H.B.; Walker, D.W. Promoting Drp1-mediated mitochondrial fission in midlife prolongs healthy lifespan of Drosophila melanogaster. Nat. Commun. 2017, 8, 1-14. [CrossRef]

131. Sabbah, H.N. Targeting mitochondrial dysfunction in the treatment of heart failure. Expert Rev. Cardiovasc. Ther. 2016, 14, 1305-1313. [CrossRef]

132. Dorn Ii, G.W. Mitochondrial dynamics in heart disease. Biochim. Et Biophys. Acta Mol. Cell Res. 2013, 1833, 233-241. [CrossRef] 
133. Park, S.; Won, J.-H.; Hwang, I.; Hong, S.; Lee, H.K.; Yu, J.-W. Defective mitochondrial fission augments NLRP3 inflammasome activation. Sci. Rep. 2015, 5, 15489. [CrossRef]

134. Ichinohe, T.; Yamazaki, T.; Koshiba, T.; Yanagi, Y. Mitochondrial protein mitofusin 2 is required for NLRP3 inflammasome activation after RNA virus infection. Proc. Natl. Acad. Sci. USA 2013, 110, 17963-17968. [CrossRef]

135. Miller, C.; Ferrero, M.; Bers, D.M.; Dedkova, E.N. Mitochondrial quality control in aging and heart failure: Influence of ketone bodies. Biophys. J. 2018, 114, 661a-662a. [CrossRef]

136. Ding, W.-X.; Yin, X.-M. Mitophagy: Mechanisms, pathophysiological roles, and analysis. Biol. Chem. 2012, 393, 547-564. [CrossRef] [PubMed]

137. Springer, M.Z.; Macleod, K.F. In Brief: Mitophagy: Mechanisms and role in human disease. J. Pathol. 2016, 240, 253-255. [CrossRef] [PubMed]

138. Shires, S.E.; Gustafsson, Å.B. Mitophagy and heart failure. J. Mol. Med. 2015, 93, 253-262. [CrossRef] [PubMed]

139. Morciano, G.; Patergnani, S.; Bonora, M.; Pedriali, G.; Tarocco, A.; Bouhamida, E.; Marchi, S.; Ancora, G.; Anania, G.; Wieckowski, M.R. Mitophagy in Cardiovascular Diseases. J. Clin. Med. 2020, 9, 892. [CrossRef]

140. Kubli, D.A.; Quinsay, M.N.; Gustafsson, Å.B. Parkin deficiency results in accumulation of abnormal mitochondria in aging myocytes. Commun. Integr. Biol. 2013, 6, e24511. [CrossRef]

141. Shirakabe, A.; Ikeda, Y.; Sciarretta, S.; Zablocki, D.K.; Sadoshima, J. Aging and autophagy in the heart. Circ. Res. 2016, 118, 1563-1576. [CrossRef] [PubMed]

142. Wang, B.; Nie, J.; Wu, L.; Hu, Y.; Wen, Z.; Dong, L.; Zou, M.-H.; Chen, C.; Wang, D.W. AMPK $\alpha 2$ protects against the development of heart failure by enhancing mitophagy via PINK1 phosphorylation. Circ. Res. 2018, 122, 712-729. [CrossRef] [PubMed]

143. Fang, E.F.; Hou, Y.; Lautrup, S.; Jensen, M.B.; Yang, B.; SenGupta, T.; Caponio, D.; Khezri, R.; Demarest, T.G.; Aman, Y. NAD+ augmentation restores mitophagy and limits accelerated aging in Werner syndrome. Nat. Commun. 2019, 10, 1-18. [CrossRef] [PubMed]

144. Liang, W.J.; Gustafsson, Å.B. The Aging Heart: Mitophagy at the Center of Rejuvenation. Front. Cardiovasc. Med. 2020, 7, 18. [CrossRef] [PubMed]

145. Ryu, D.; Mouchiroud, L.; Andreux, P.A.; Katsyuba, E.; Moullan, N.; Nicolet-dit-Félix, A.A.; Williams, E.G.; Jha, P.; Sasso, G.L.; Huzard, D. Urolithin A induces mitophagy and prolongs lifespan in C. elegans and increases muscle function in rodents. Nat. Med. 2016, 22, 879. [CrossRef] [PubMed]

146. Kim, M.-J.; Yoon, J.-H.; Ryu, J.-H. Mitophagy: A balance regulator of NLRP3 inflammasome activation. BMB Rep. 2016, 49, 529. [CrossRef] [PubMed]

147. Zhong, Z.; Umemura, A.; Sanchez-Lopez, E.; Liang, S.; Shalapour, S.; Wong, J.; He, F.; Boassa, D.; Perkins, G.; Ali, S.R. NF- $\mathrm{kB}$ restricts inflammasome activation via elimination of damaged mitochondria. Cell 2016, 164, 896-910. [CrossRef] [PubMed]

148. He, Q.; Li, Z.; Meng, C.; Wu, J.; Zhao, Y.; Zhao, J. Parkin-Dependent Mitophagy Is Required for the Inhibition of ATF4 on NLRP3 Inflammasome Activation in Cerebral Ischemia-Reperfusion Injury in Rats. Cells 2019, 8, 897. [CrossRef] [PubMed]

149. Siasos, G.; Tsigkou, V.; Kosmopoulos, M.; Theodosiadis, D.; Simantiris, S.; Tagkou, N.M.; Tsimpiktsioglou, A.; Stampouloglou, P.K.; Oikonomou, E.; Mourouzis, K. Mitochondria and cardiovascular diseases-from pathophysiology to treatment. Ann. Transl. Med. 2018, 6, 256. [CrossRef] [PubMed]

150. Yang, S.; Xia, C.; Li, S.; Du, L.; Zhang, L.; Zhou, R. Defective mitophagy driven by dysregulation of rheb and KIF5B contributes to mitochondrial reactive oxygen species (ROS)-induced nod-like receptor 3 (NLRP3) dependent proinflammatory response and aggravates lipotoxicity. Redox Biol. 2014, 3, 63-71. [CrossRef]

151. Thevaranjan, N.; Puchta, A.; Schulz, C.; Naidoo, A.; Szamosi, J.C.; Verschoor, C.P.; Loukov, D.; Schenck, L.P.; Jury, J.; Foley, K.P. Age-associated microbial dysbiosis promotes intestinal permeability, systemic inflammation, and macrophage dysfunction. Cell Host Microbe 2017, 21, 455-466. [CrossRef]

152. Biernacka, A.; Frangogiannis, N.G. Aging and cardiac fibrosis. Aging Dis. 2011, 2, 158.

153. Dewan, S.K.; Zheng, S.-B.; Xia, S.-J.; Kalionis, B. Senescent remodeling of the immune system and its contribution to the predisposition of the elderly to infections. Chin. Med. J. 2012, 125, 3325-3331.

154. Feldman, N.; Rotter-Maskowitz, A.; Okun, E. DAMPs as mediators of sterile inflammation in aging-related pathologies. Ageing Res. Rev. 2015, 24, 29-39. [CrossRef] 
155. Deleidi, M.; Jäggle, M.; Rubino, G. Immune aging, dysmetabolism, and inflammation in neurological diseases. Front. Neurosci. 2015, 9, 172. [CrossRef]

156. Ramos, G.C.; Van Den Berg, A.; Nunes-Silva, V.; Weirather, J.; Peters, L.; Burkard, M.; Friedrich, M.; Pinnecker, J.; Abeßer, M.; Heinze, K.G. Myocardial aging as a T-cell-mediated phenomenon. Proc. Natl. Acad. Sci. USA 2017, 114, E2420-E2429. [CrossRef] [PubMed]

157. Harari, E.; Guo, L.; Smith, S.L.; Braumann, R.E.; Virmani, R.; Finn, A.V. Heart-resident macrophages: Are they involved in the rhythm of every beat? J. Thorac. Dis. 2017, 9, 2264. [CrossRef] [PubMed]

158. Oishi, Y.; Manabe, I. Macrophages in age-related chronic inflammatory diseases. NPJ Aging Mech. Dis. 2016, 2, 1-8. [CrossRef]

159. Honold, L.; Nahrendorf, M. Resident and monocyte-derived macrophages in cardiovascular disease. Circ. Res. 2018, 122, 113-127. [CrossRef] [PubMed]

160. O'Rourke, S.; Dunne, A.; Monaghan, M.G. The role of macrophages in the infarcted myocardium: Orchestrators of ECM remodelling. Front. Cardiovasc. Med. 2019, 6, 101. [CrossRef] [PubMed]

161. Wang, Z.; Koenig, A.L.; Lavine, K.J.; Apte, R.S. Macrophage Plasticity and Function in the Eye and Heart. Trends Immunol. 2019, 40, 825-841. [CrossRef]

162. Yap, J.; Cabrera-Fuentes, H.A.; Irei, J.; Hausenloy, D.J.; Boisvert, W.A. Role of Macrophages in Cardioprotection. Int. J. Mol. Sci. 2019, 20, 2474. [CrossRef]

163. Molawi, K.; Wolf, Y.; Kandalla, P.K.; Favret, J.; Hagemeyer, N.; Frenzel, K.; Pinto, A.R.; Klapproth, K.; Henri, S.; Malissen, B. Progressive replacement of embryo-derived cardiac macrophages with age. J. Exp. Med. 2014, 211, 2151-2158. [CrossRef]

164. DeBerge, M.; Shah, S.J.; Wilsbacher, L.; Thorp, E. Macrophages in heart failure with reduced versus preserved ejection fraction. Trends Mol. Med. 2019, 25, 328-340. [CrossRef]

165. Pinto, A.R.; Godwin, J.W.; Chandran, A.; Hersey, L.; Ilinykh, A.; Debuque, R.; Wang, L.; Rosenthal, N.A. Age-related changes in tissue macrophages precede cardiac functional impairment. Aging 2014, 6, 399. [CrossRef]

166. Toba, H.; Cannon, P.L.; Yabluchanskiy, A.; Iyer, R.P.; D’Armiento, J.; Lindsey, M.L. Transgenic overexpression of macrophage matrix metalloproteinase-9 exacerbates age-related cardiac hypertrophy, vessel rarefaction, inflammation, and fibrosis. Am. J. Physiol. Heart Circ. Physiol. 2017, 312, H375-H383. [CrossRef] [PubMed]

167. Huang, J.; Xie, Y.; Sun, X.; Zeh Iii, H.J.; Kang, R.; Lotze, M.T.; Tang, D. DAMPs, ageing, and cancer: The 'DAMP Hypothesis'. Ageing Res. Rev. 2015, 24, 3-16. [CrossRef] [PubMed]

168. Goldberg, E.L.; Dixit, V.D. Drivers of age-related inflammation and strategies for healthspan extension. Immunol. Rev. 2015, 265, 63-74. [CrossRef] [PubMed]

169. Kang, Y.; Zhang, H.; Zhao, Y.; Wang, Y.; Wang, W.; He, Y.; Zhang, W.; Zhang, W.; Zhu, X.; Zhou, Y. Telomere dysfunction disturbs macrophage mitochondrial metabolism and the NLRP3 inflammasome through the PGC-1 $\alpha$ /TNFAIP3 axis. Cell Rep. 2018, 22, 3493-3506. [CrossRef]

170. Van Beek, A.A.; Van den Bossche, J.; Mastroberardino, P.G.; de Winther, M.P.J.; Leenen, P.J.M. Metabolic alterations in aging macrophages: Ingredients for inflammaging? Trends Immunol. 2019, 40, 113-127. [CrossRef]

171. Woodcock, K.J.; Kierdorf, K.; Pouchelon, C.A.; Vivancos, V.; Dionne, M.S.; Geissmann, F. Macrophage-derived upd 3 cytokine causes impaired glucose homeostasis and reduced lifespan in Drosophila fed a lipid-rich diet. Immunity 2015, 42, 133-144. [CrossRef]

172. Spadaro, O.; Goldberg, E.L.; Camell, C.D.; Youm, Y.-H.; Kopchick, J.J.; Nguyen, K.Y.; Bartke, A.; Sun, L.Y.; Dixit, V.D. Growth hormone receptor deficiency protects against age-related NLRP3 inflammasome activation and immune senescence. Cell Rep. 2016, 14, 1571-1580. [CrossRef]

173. Sokoła-Wysoczańska, E.; Wysoczański, T.; Wagner, J.; Czyż, K.; Bodkowski, R.; Lochyński, S.; Patkowska-Sokoła, B. Polyunsaturated fatty acids and their potential therapeutic role in cardiovascular system disorders-A review. Nutrients 2018, 10, 1561. [CrossRef]

174. Rodríguez, M.G.; Rebollar, P.; Mattioli, S.; Castellini, C. n-3 PUFA sources (precursor/products): A review of current knowledge on rabbit. Animals 2019, 9, 806.

175. Ander, B.P.; Dupasquier, C.M.C.; Prociuk, M.A.; Pierce, G.N. Polyunsaturated fatty acids and their effects on cardiovascular disease. Exp. Clin. Cardiol. 2003, 8, 164. 
176. Liu, J.J.; Green, P.; Mann, J.J.; Rapoport, S.I.; Sublette, M.E. Pathways of polyunsaturated fatty acid utilization: Implications for brain function in neuropsychiatric health and disease. Brain Res. 2015, 1597, 220-246. [CrossRef] [PubMed]

177. Dyall, S.C. Interplay between n-3 and n-6 long-chain polyunsaturated fatty acids and the endocannabinoid system in brain protection and repair. Lipids 2017, 52, 885-900. [CrossRef] [PubMed]

178. Fisslthaler, B.; Popp, R.; Kiss, L.; Potente, M.; Harder, D.R.; Fleming, I.; Busse, R. Cytochrome P450 2C is an EDHF synthase in coronary arteries. Nature 1999, 401, 493-497. [CrossRef] [PubMed]

179. Westphal, C.; Konkel, A.; Schunck, W.-H. Cytochrome p450 Enzymes in the Bioactivation of Polyunsaturated Fatty Acids and Their Role in Cardiovascular Disease. In Monooxygenase, Peroxidase and Peroxygenase Properties and Mechanisms of Cytochrome P450; Springer: Berlin/Heidelberg, Germany, 2015; pp. 151-187.

180. Schunck, W.-H.; Konkel, A.; Fischer, R.; Weylandt, K.-H. Therapeutic potential of omega-3 fatty acid-derived epoxyeicosanoids in cardiovascular and inflammatory diseases. Pharm. Ther. 2018, 183, 177-204. [CrossRef]

181. Katragadda, D.; Batchu, S.N.; Cho, W.J.; Chaudhary, K.R.; Falck, J.R.; Seubert, J.M. Epoxyeicosatrienoic acids limit damage to mitochondrial function following stress in cardiac cells. J. Mol. Cell. Cardiol. 2009, 46, 867-875. [CrossRef]

182. Nayeem, M.A. Role of oxylipins in cardiovascular diseases. Acta Pharm. Sin. 2018, 39, 1142-1154. [CrossRef]

183. Samokhvalov, V.; Alsaleh, N.; El-Sikhry, H.E.; Jamieson, K.L.; Chen, C.B.; Lopaschuk, D.G.; Carter, C.; Light, P.E.; Manne, R.; Falck, J.R. Epoxyeicosatrienoic acids protect cardiac cells during starvation by modulating an autophagic response. Cell Death Dis. 2013, 4, e885. [CrossRef] [PubMed]

184. Ulu, A.; Lee, K.S.S.; Miyabe, C.; Yang, J.; Hammock, B.G.; Dong, H.; Hammock, B.D. An omega-3 epoxide of docosahexaenoic acid lowers blood pressure in angiotensin-II dependent hypertension. J. Cardiovasc. Pharm. 2014, 64, 87. [CrossRef]

185. Wang, R.-X.; Chai, Q.; Lu, T.; Lee, H.-C. Activation of vascular BK channels by docosahexaenoic acid is dependent on cytochrome P450 epoxygenase activity. Cardiovasc. Res. 2011, 90, 344-352. [CrossRef]

186. Thomson, S.J.; Askari, A.; Bishop-Bailey, D. Anti-inflammatory effects of epoxyeicosatrienoic acids. Int. J. Vasc. Med. 2012, 2012. [CrossRef]

187. Jamieson, K.L.; Endo, T.; Darwesh, A.M.; Samokhvalov, V.; Seubert, J.M. Cytochrome P450-derived eicosanoids and heart function. Pharm. Ther. 2017, 179, 47-83. [CrossRef] [PubMed]

188. Hrdlicka, J.; Neckář, J.; Papousek, F.; Huskova, Z.; Kikerlova, S.; Vanourkova, Z.; Vernerova, Z.; Vasinova, J.; Hammock, B.D.; Hwang, S.H. Epoxyeicosatrienoic acid-based therapy attenuate the progression of postischemic heart failure in normotensive Sprague-Dawley but not in hypertensive Ren-2 transgenic rats. Front. Pharm. 2019, 10, 159. [CrossRef] [PubMed]

189. Imig, J.D. Prospective for cytochrome P450 epoxygenase cardiovascular and renal therapeutics. Pharm. Ther. 2018, 192, 1-19. [CrossRef]

190. Imig, J.D.; Hammock, B.D. Soluble epoxide hydrolase as a therapeutic target for cardiovascular diseases. Nat. Rev. Drug Discov. 2009, 8, 794-805. [CrossRef] [PubMed]

191. Cao, J.; Tsenovoy, P.L.; Thompson, E.A.; Falck, J.R.; Touchon, R.; Sodhi, K.; Rezzani, R.; Shapiro, J.I.; Abraham, N.G. Agonists of epoxyeicosatrienoic acids reduce infarct size and ameliorate cardiac dysfunction via activation of HO-1 and Wnt1 canonical pathway. Prostaglandins Other Lipid Mediat. 2015, 116, 76-86. [CrossRef] [PubMed]

192. Neckář, J.; Hye Khan, M.A.; Gross, G.J.; Cyprová, M.; Hrdlička, J.; Kvasilová, A.; Falck, J.R.; Campbell, W.B.; Sedláková, L.; Škutová, Š. Epoxyeicosatrienoic acid analog EET-B attenuates post-myocardial infarction remodeling in spontaneously hypertensive rats. Clin. Sci. 2019, 133, 939-951. [CrossRef] [PubMed]

193. Xu, D.; Li, N.; He, Y.; Timofeyev, V.; Lu, L.; Tsai, H.-J.; Kim, I.-H.; Tuteja, D.; Mateo, R.K.P.; Singapuri, A. Prevention and reversal of cardiac hypertrophy by soluble epoxide hydrolase inhibitors. Proc. Natl. Acad. Sci. USA 2006, 103, 18733-18738. [CrossRef]

194. Westphal, C.; Spallek, B.; Konkel, A.; Marko, L.; Qadri, F.; DeGraff, L.M.; Schubert, C.; Bradbury, J.A.; Regitz-Zagrosek, V.; Falck, J.R. CYP2J2 overexpression protects against arrhythmia susceptibility in cardiac hypertrophy. PLoS ONE 2013, 8, e73490. [CrossRef]

195. He, Z.; Zhang, X.; Chen, C.; Wen, Z.; Hoopes, S.L.; Zeldin, D.C.; Wang, D.W. Cardiomyocyte-specific expression of CYP2J2 prevents development of cardiac remodelling induced by angiotensin II. Cardiovasc. Res. 2015, 105, 304-317. [CrossRef] 
196. O'Shea, K.M.; Chess, D.J.; Khairallah, R.J.; Hecker, P.A.; Lei, B.; Walsh, K.; Des Rosiers, C.; Stanley, W.C. $\omega-3$ Polyunsaturated fatty acids prevent pressure overload-induced ventricular dilation and decrease in mitochondrial enzymes despite no change in adiponectin. Lipids Health Dis. 2010, 9, 95. [CrossRef]

197. Darwesh, A.M.; Sosnowski, D.K.; Lee, T.Y.T.; Keshavarz-Bahaghighat, H.; Seubert, J.M. Insights into the cardioprotective properties of n-3 PUFAs against ischemic heart disease via modulation of the innate immune system. Chem. Biol. Interact. 2019, 308, 20-44. [CrossRef] [PubMed]

198. Romagna, E. Effect of n-3 Polyunsaturated Fatty Acids in Patients with Chronic Heart Failure (the GISSI-HF Trial): A Randomised, Double-Blind, Placebo-Controlled Trial. Lancet 2008, 372, 1223-1230.

199. Kromhout, D.; Giltay, E.J.; Geleijnse, J.M.; Alpha Omega Trial, G. n-3 fatty acids and cardiovascular events after myocardial infarction. N. Engl. J. Med. 2010, 363, 2015-2026. [CrossRef] [PubMed]

200. Block, R.C.; Liu, L.; Herrington, D.M.; Huang, S.; Tsai, M.Y.; O'Connell, T.D.; Shearer, G.C. Predicting risk for incident heart failure with omega-3 fatty acids: From MESA. JACC Heart Fail. 2019, 7, 651-661. [CrossRef] [PubMed]

201. Piotrowski, J.; Jędrzejewski, T.; Pawlikowska, M.; Pacuła, A.J.; Ścianowski, J.; Kozak, W. The weakening effect of soluble epoxide hydrolase inhibitor AUDA on febrile response to lipopolysaccharide and turpentine in rat. J. Physiol. Biochem. 2017, 73, 551-560. [CrossRef] [PubMed]

202. Ai, D.; Pang, W.; Li, N.; Xu, M.; Jones, P.D.; Yang, J.; Zhang, Y.; Chiamvimonvat, N.; Shyy, J.Y.J.; Hammock, B.D. Soluble epoxide hydrolase plays an essential role in angiotensin II-induced cardiac hypertrophy. Proc. Natl. Acad. Sci. USA 2009, 106, 564-569. [CrossRef]

203. Akhnokh, M.K.; Yang, F.H.; Samokhvalov, V.; Jamieson, K.L.; Cho, W.J.; Wagg, C.; Takawale, A.; Wang, X.; Lopaschuk, G.D.; Hammock, B.D. Inhibition of soluble epoxide hydrolase limits mitochondrial damage and preserves function following ischemic injury. Front. Pharm. 2016, 7, 133. [CrossRef]

204. Darwesh, A.M.; Keshavarz-Bahaghighat, H.; Jamieson, K.L.; Seubert, J.M. Genetic Deletion or Pharmacological Inhibition of Soluble Epoxide Hydrolase Ameliorates Cardiac Ischemia/Reperfusion Injury by Attenuating NLRP3 Inflammasome Activation. Int. J. Mol. Sci. 2019, 20, 3502. [CrossRef]

205. Imig, J.D.; Zhao, X.; Capdevila, J.H.; Morisseau, C.; Hammock, B.D. Soluble epoxide hydrolase inhibition lowers arterial blood pressure in angiotensin II hypertension. Hypertension 2002, 39, 690-694. [CrossRef]

206. Jamieson, K.L.; Samokhvalov, V.; Akhnokh, M.K.; Lee, K.; Cho, W.J.; Takawale, A.; Wang, X.; Kassiri, Z.; Seubert, J.M. Genetic deletion of soluble epoxide hydrolase provides cardioprotective responses following myocardial infarction in aged mice. Prostaglandins Other Lipid Mediat. 2017, 132, 47-58. [CrossRef]

207. Ulu, A.; Davis, B.B.; Tsai, H.-J.; Kim, I.-H.; Morisseau, C.; Inceoglu, B.; Fiehn, O.; Hammock, B.D.; Weiss, R.H. Soluble epoxide hydrolase inhibitors reduce the development of atherosclerosis in apolipoprotein e-knockout mouse model. J. Cardiovasc. Pharm. 2008, 52, 314. [CrossRef] [PubMed]

208. Merabet, N.; Bellien, J.; Glevarec, E.; Nicol, L.; Lucas, D.; Remy-Jouet, I.; Bounoure, F.; Dreano, Y.; Wecker, D.; Thuillez, C. Soluble epoxide hydrolase inhibition improves myocardial perfusion and function in experimental heart failure. J. Mol. Cell. Cardiol. 2012, 52, 660-666. [CrossRef]

209. Stevenson, M.D.; Canugovi, C.; Vendrov, A.E.; Hayami, T.; Bowles, D.E.; Krause, K.-H.; Madamanchi, N.R.; Runge, M.S. NADPH oxidase 4 regulates inflammation in ischemic heart failure: Role of soluble epoxide hydrolase. Antioxid. Redox Signal. 2019, 31, 39-58. [CrossRef] [PubMed]

210. Vacková, Š.; Kopkan, L.; Kikerlová, S.; Husková,Z.; Sadowski, J.; Kompanowska-Jezierska, E.; Hammock, B.D.; Imig, J.D.; Táborský, M.; Melenovský, V. Pharmacological blockade of soluble epoxide hydrolase attenuates the progression of congestive heart failure combined with chronic kidney disease: Insights from studies with Fawn-hooded hypertensive rats. Front. Pharm. 2019, 10, 18. [CrossRef] [PubMed]

211. Zhang, K.; Liu, Y.; Liu, X.; Chen, J.; Cai, Q.; Wang, J.; Huang, H. Apocynin improving cardiac remodeling in chronic renal failure disease is associated with up-regulation of epoxyeicosatrienoic acids. Oncotarget 2015, 6, 24699. [CrossRef] [PubMed]

212. Samokhvalov, V.; Jamieson, K.L.; Darwesh, A.M.; Keshavarz-Bahaghighat, H.; Lee, T.Y.T.; Edin, M.; Lih, F.; Zeldin, D.C.; Seubert, J.M. Deficiency of Soluble Epoxide Hydrolase Protects Cardiac Function Impaired by LPS-Induced Acute Inflammation. Front. Pharm. 2019, 9, 1572. [CrossRef]

213. Bannehr, M.; Löhr, L.; Gelep, J.; Haverkamp, W.; Schunck, W.-H.; Gollasch, M.; Wutzler, A. Linoleic acid metabolite DiHOME decreases post-ischemic cardiac recovery in murine hearts. Cardiovasc. Toxicol. 2019, 19, 365-371. [CrossRef] 
214. Ha, J.; Dobretsov, M.; Kurten, R.C.; Grant, D.F.; Stimers, J.R. Effect of linoleic acid metabolites on Na+/K+ pump current in N20. 1 oligodendrocytes: Role of membrane fluidity. Toxicol. Appl. Pharm. 2002, 182, 76-83. [CrossRef]

215. Harrell, M.D.; Stimers, J.R. Differential effects of linoleic acid metabolites on cardiac sodium current. J. Pharm. Exp. Ther. 2002, 303, 347-355. [CrossRef]

216. Stimers, J.R.; Dobretsov, M.; Hastings, S.L.; Jude, A.R.; Grant, D.F. Effects of linoleic acid metabolites on electrical activity in adult rat ventricular myocytes. Biochim. Et Biophys. Acta Mol. Cell Biol. Lipids 1999, 1438, 359-368. [CrossRef]

217. Chaudhary, K.R.; Zordoky, B.N.M.; Edin, M.L.; Alsaleh, N.; El-Kadi, A.O.S.; Zeldin, D.C.; Seubert, J.M. Differential effects of soluble epoxide hydrolase inhibition and CYP2J2 overexpression on postischemic cardiac function in aged mice. Prostaglandins Other Lipid Mediat. 2013, 104, 8-17. [CrossRef] [PubMed]

218. Edin, M.L.; Wang, Z.; Bradbury, J.A.; Graves, J.P.; Lih, F.B.; DeGraff, L.M.; Foley, J.F.; Torphy, R.; Ronnekleiv, O.K.; Tomer, K.B. Endothelial expression of human cytochrome P450 epoxygenase CYP2C8 increases susceptibility to ischemia-reperfusion injury in isolated mouse heart. FASEB J. 2011, 25, 3436-3447. [CrossRef] [PubMed]

219. Node, K.; Huo, Y.; Ruan, X.; Yang, B.; Spiecker, M.; Ley, K.; Zeldin, D.C.; Liao, J.K. Anti-inflammatory properties of cytochrome P450 epoxygenase-derived eicosanoids. Science 1999, 285, 1276-1279. [CrossRef]

220. Shoieb, S.M.; El-Ghiaty, M.A.; Alqahtani, M.A.; El-Kadi, A.O.S. Cytochrome P450-derived eicosanoids and inflammation in liver diseases. Prostaglandins Other Lipid Mediat. 2020, 147, 106400. [CrossRef]

221. Li, X.; Zhu, F.; Meng, W.; Zhang, F.; Hong, J.; Zhang, G.; Wang, F. CYP2J2/EET reduces vulnerability to atrial fibrillation in chronic pressure overload mice. J. Cell. Mol. Med. 2020, 24, 862-874. [CrossRef] [PubMed]

222. Darwesh, A.M.; Jamieson, K.L.; Wang, C.; Samokhvalov, V.; Seubert, J.M. Cardioprotective effects of CYP-derived epoxy metabolites of docosahexaenoic acid involve limiting NLRP3 inflammasome activation (1). Can. J. Physiol Pharm. 2019, 97, 544-556. [CrossRef]

223. Capozzi, M.E.; Hammer, S.S.; McCollum, G.W.; Penn, J.S. Epoxygenated fatty acids inhibit retinal vascular inflammation. Sci. Rep. 2016, 6, 39211. [CrossRef]

224. Talukdar, S.; Bae, E.J.; Imamura, T.; Morinaga, H.; Fan, W.; Li, P.; Lu, W.J.; Watkins, S.M.; Olefsky, J.M. GPR120 is an omega-3 fatty acid receptor mediating potent anti-inflammatory and insulin-sensitizing effects. Cell 2010, 142, 687-698.

225. Ramos-Campo, D.J.; Ávila-Gandía, V.; López-Román, F.J.; Miñarro, J.; Contreras, C.; Soto-Méndez, F.; Domingo Pedrol, J.C.; Luque-Rubia, A.J. Supplementation of Re-Esterified Docosahexaenoic and Eicosapentaenoic Acids Reduce Inflammatory and Muscle Damage Markers after Exercise in Endurance Athletes: A Randomized, Controlled Crossover Trial. Nutrients 2020, 12, 719. [CrossRef]

226. Ulu, A.; Harris, T.R.; Morisseau, C.; Miyabe, C.; Inoue, H.; Schuster, G.; Dong, H.; Iosif, A.-M.; Liu, J.-Y.; Weiss, R.H. Anti-inflammatory effects of omega-3 polyunsaturated fatty acids and soluble epoxide hydrolase inhibitors in angiotensin-II dependent hypertension. J. Cardiovasc. Pharm. 2013, 62, 285. [CrossRef]

227. Napimoga, M.H.; Rocha, E.P.; Trindade-da-Silva, C.A.; Demasi, A.P.D.; Martinez, E.F.; Macedo, C.G.; Abdalla, H.B.; Bettaieb, A.; Haj, F.G.; Clemente-Napimoga, J.T. Soluble epoxide hydrolase inhibitor promotes immunomodulation to inhibit bone resorption. J. Periodontal Res. 2018, 53, 743-749. [CrossRef] [PubMed]

228. Wagner, K.M.; McReynolds, C.B.; Schmidt, W.K.; Hammock, B.D. Soluble epoxide hydrolase as a therapeutic target for pain, inflammatory and neurodegenerative diseases. Pharm. Ther. 2017, 180, 62-76. [CrossRef] [PubMed]

229. Yang, J.; Bratt, J.; Franzi, L.; Liu, J.-Y.; Zhang, G.; Zeki, A.A.; Vogel, C.F.A.; Williams, K.; Dong, H.; Lin, Y. Soluble epoxide hydrolase inhibitor attenuates inflammation and airway hyperresponsiveness in mice. Am. J. Respir. Cell Mol. Biol. 2015, 52, 46-55. [CrossRef] [PubMed]

230. Schmelzer, K.R.; Kubala, L.; Newman, J.W.; Kim, I.H.; Eiserich, J.P.; Hammock, B.D. Soluble epoxide hydrolase is a therapeutic target for acute inflammation. Proc. Natl Acad Sci. USA 2005, 102, 9772-9777. [CrossRef]

231. Zhang, W.; Yang, A.L.; Liao, J.; Li, H.; Dong, H.; Chung, Y.T.; Bai, H.; Matkowskyj, K.A.; Hammock, B.D.; Yang, G.-Y. Soluble epoxide hydrolase gene deficiency or inhibition attenuates chronic active inflammatory bowel disease in IL-10 (-/-) mice. Dig. Dis. Sci. 2012, 57, 2580-2591. [CrossRef]

232. Yeh, C.-F.; Chuang, T.Y.; Hung, Y.-W.; Lan, M.-Y.; Tsai, C.-H.; Huang, H.-X.; Lin, Y.-Y. Soluble epoxide hydrolase inhibition enhances anti-inflammatory and antioxidative processes, modulates microglia polarization, and promotes recovery after ischemic stroke. Neuropsychiatr. Dis. Treat. 2019, 15, 2927. [CrossRef] 
233. Yang, H.-H.; Duan, J.-X.; Liu, S.-K.; Xiong, J.-B.; Guan, X.-X.; Zhong, W.-J.; Sun, C.-C.; Zhang, C.-Y.; Luo, X.-Q.; Zhang, Y.-F. A COX-2/sEH dual inhibitor PTUPB alleviates lipopolysaccharide-induced acute lung injury in mice by inhibiting NLRP3 inflammasome activation. Theranostics 2020, 10, 4749. [CrossRef]

234. Zimmer, B.; Angioni, C.; Osthues, T.; Toewe, A.; Thomas, D.; Pierre, S.C.; Geisslinger, G.; Scholich, K.; Sisignano, M. The oxidized linoleic acid metabolite 12, 13-DiHOME mediates thermal hyperalgesia during inflammatory pain. Biochim. Et Biophys. Acta Mol. Cell Biol. Lipids 2018, 1863, 669-678. [CrossRef]

235. Levan, S.R. Neonatal gut-microbiome-derived 12, 13 DiHOME impedes tolerance and promotes childhood atopy and asthma. Biorxiv 2018, e311704. [CrossRef]

236. Levan, S.R.; Stamnes, K.A.; Lin, D.L.; Panzer, A.R.; Fukui, E.; McCauley, K.; Fujimura, K.E.; McKean, M.; Ownby, D.R.; Zoratti, E.M. Elevated faecal 12, 13-diHOME concentration in neonates at high risk for asthma is produced by gut bacteria and impedes immune tolerance. Nat. Microbiol. 2019, 4, 1851-1861. [CrossRef]

237. Picca, A.; Lezza, A.M.S.; Leeuwenburgh, C.; Pesce, V.; Calvani, R.; Landi, F.; Bernabei, R.; Marzetti, E. Fueling inflamm-aging through mitochondrial dysfunction: Mechanisms and molecular targets. Int. J. Mol. Sci. 2017, 18, 933. [CrossRef] [PubMed]

238. Batchu, S.N.; Lee, S.B.; Samokhvalov, V.; Chaudhary, K.R.; El-Sikhry, H.; Weldon, S.M.; Seubert, J.M. Novel soluble epoxide hydrolase inhibitor protects mitochondrial function following stress. Can. J. Physiol. Pharm. 2012, 90, 811-823. [CrossRef] [PubMed]

239. Chaudhary, K.R.; Cho, W.J.; Yang, F.; Samokhvalov, V.; El-Sikhry, H.E.; Daniel, E.E.; Seubert, J.M. Effect of ischemia reperfusion injury and epoxyeicosatrienoic acids on caveolin expression in mouse myocardium. J. Cardiovasc. Pharm. 2013, 61, 258-263. [CrossRef] [PubMed]

240. El-Sikhry, H.E.; Alsaleh, N.; Dakarapu, R.; Falck, J.R.; Seubert, J.M. Novel roles of epoxyeicosanoids in regulating cardiac mitochondria. PloS ONE 2016, 11, e0160380. [CrossRef]

241. Oni-Orisan, A.; Alsaleh, N.; Lee, C.R.; Seubert, J.M. Epoxyeicosatrienoic acids and cardioprotection: The road to translation. J. Mol. Cell. Cardiol. 2014, 74, 199-208. [CrossRef]

242. Batchu, S.N.; Lee, S.B.; Qadhi, R.S.; Chaudhary, K.R.; El-Sikhry, H.; Kodela, R.; Falck, J.R.; Seubert, J.M. Cardioprotective effect of a dual acting epoxyeicosatrienoic acid analogue towards ischaemia reperfusion injury. Br. J. Pharm. 2011, 162, 897-907. [CrossRef]

243. Sarkar, P.; Zaja, I.; Bienengraeber, M.; Rarick, K.R.; Terashvili, M.; Canfield, S.; Falck, J.R.; Harder, D.R. Epoxyeicosatrienoic acids pretreatment improves amyloid $\beta$-induced mitochondrial dysfunction in cultured rat hippocampal astrocytes. Am. J. Physiol. Heart Circ. Physiol. 2014, 306, H475-H484. [CrossRef]

244. Chen, W.; Zheng, G.; Yang, S.; Ping, W.; Fu, X.; Zhang, N.; Wang, D.W.; Wang, J. CYP2J2 and EETs protect against oxidative stress and apoptosis in vivo and in vitro following lung ischemia/reperfusion. Cell. Physiol. Biochem. 2014, 33, 1663-1680. [CrossRef]

245. Cao, J.; Singh, S.P.; McClung, J.A.; Joseph, G.; Vanella, L.; Barbagallo, I.; Jiang, H.; Falck, J.R.; Arad, M.; Shapiro, J.I. EET intervention on Wnt1, NOV, and HO-1 signaling prevents obesity-induced cardiomyopathy in obese mice. Am. J. Physiol. Heart Circ. Physiol. 2017, 313, H368-H380. [CrossRef]

246. Liu, L.; Puri, N.; Raffaele, M.; Schragenheim, J.; Singh, S.P.; Bradbury, J.A.; Bellner, L.; Vanella, L.; Zeldin, D.C.; Cao, J. Ablation of soluble epoxide hydrolase reprogram white fat to beige-like fat through an increase in mitochondrial integrity, HO-1-adiponectin in vitro and in vivo. Prostaglandins Other Lipid Mediat. 2018, 138, 1-8. [CrossRef]

247. Galvao, T.F.; Khairallah, R.J.; Dabkowski, E.R.; Brown, B.H.; Hecker, P.A.; O'Connell, K.A.; O'Shea, K.M.; Sabbah, H.N.; Rastogi, S.; Daneault, C. Marine n3 polyunsaturated fatty acids enhance resistance to mitochondrial permeability transition in heart failure but do not improve survival. Am. J. Physiol. Heart Circ. Physiol. 2013, 304, H12-H21. [CrossRef]

248. Stanley, W.C.; Khairallah, R.J.; Dabkowski, E.R. Update on lipids and mitochondrial function: Impact of dietary n-3 polyunsaturated fatty acids. Curr. Opin. Clin. Nutr. Metab. Care 2012, 15, 122. [CrossRef]

249. Dabkowski, E.R.; O'Connell, K.A.; Xu, W.; Ribeiro, R.F.; Hecker, P.A.; Shekar, K.C.; Daneault, C.; Des Rosiers, C.; Stanley, W.C. Docosahexaenoic acid supplementation alters key properties of cardiac mitochondria and modestly attenuates development of left ventricular dysfunction in pressure overload-induced heart failure. Cardiovasc. Drugs Ther. 2013, 27, 499-510. [CrossRef] [PubMed]

250. Zhang, Y.; Jiang, L.; Hu, W.; Zheng, Q.; Xiang, W. Mitochondrial dysfunction during in vitro hepatocyte steatosis is reversed by omega-3 fatty acid-induced up-regulation of mitofusin 2. Metabolism 2011, 60, 767-775. [CrossRef] [PubMed] 
251. Zhang, T.; Wu, P.; Zhang, J.H.; Li, Y.; Xu, S.; Wang, C.; Wang, L.; Zhang, G.; Dai, J.; Zhu, S. Docosahexaenoic acid alleviates oxidative stress-based apoptosis via improving mitochondrial dynamics in early brain injury after subarachnoid hemorrhage. Cell. Mol. Neurobiol. 2018, 38, 1413-1423. [CrossRef] [PubMed]

252. Sun, W.; Liu, C.; Chen, Q.; Liu, N.; Yan, Y.; Liu, B. SIRT3: A new regulator of cardiovascular diseases. Oxidative Med. Cell. Longev. 2018. [CrossRef] [PubMed]

253. Parodi-Rullán, R.M.; Chapa-Dubocq, X.R.; Javadov, S. Acetylation of mitochondrial proteins in the heart: The role of SIRT3. Front. Physiol. 2018, 9, 1094. [CrossRef]

254. Hafner, A.V.; Dai, J.; Gomes, A.P.; Xiao, C.-Y.; Palmeira, C.M.; Rosenzweig, A.; Sinclair, D.A. Regulation of the mPTP by SIRT3-mediated deacetylation of CypD at lysine 166 suppresses age-related cardiac hypertrophy. Aging 2010, 2, 914. [CrossRef] [PubMed]

255. Jamieson, K.L.; Keshavarz-Bahaghighat, H.; Darwesh, A.M.; Sosnowski, D.K.; Seubert, J.M. Age and Sex Differences in Hearts of Soluble Epoxide Hydrolase Null Mice. Front. Physiol. 2020, 11, 48. [CrossRef]

256. Liu, L.; Huang, X.; Gao, J.; Guo, Y.; Di, Y.; Sun, S.; Deng, X.; Cao, J. Improved endogenous epoxyeicosatrienoic acid production mends heart function via increased PGC $1 \alpha$-mitochondrial functions in metabolic syndrome. J. Pharm. Sci. 2018, 138, 138-145. [CrossRef]

257. Fajemiroye, J.O.; Cunha, L.C.d.; Saavedra-Rodríguez, R.; Rodrigues, K.L.; Naves, L.M.; Mourão, A.A.; Silva, E.F.d.; Williams, N.E.E.; Martins, J.L.R.; Sousa, R.B. Aging-induced biological changes and cardiovascular diseases. Biomed. Res. Int. 2018, 2018. [CrossRef]

258. Merz, A.A.; Cheng, S. Sex differences in cardiovascular ageing. Heart 2016, 102, 825-831. [CrossRef] [PubMed]

259. Parker, B.A.; Kalasky, M.J.; Proctor, D.N. Evidence for sex differences in cardiovascular aging and adaptive responses to physical activity. Eur. J. Appl. Physiol. 2010, 110, 235-246. [CrossRef] [PubMed]

260. Regitz-Zagrosek, V.; Kararigas, G. Mechanistic pathways of sex differences in cardiovascular disease. Physiol. Rev. 2017, 97, 1-37. [CrossRef]

261. Regitz-Zagrosek, V.; Oertelt-Prigione, S.; Seeland, U.; Hetzer, R. Sex and gender differences in myocardial hypertrophy and heart failure. Circ. J. 2010, 74, 1265-1273. [CrossRef] [PubMed]

262. Aggarwal, N.R.; Patel, H.N.; Mehta, L.S.; Sanghani, R.M.; Lundberg, G.P.; Lewis, S.J.; Mendelson, M.A.; Wood, M.J.; Volgman, A.S.; Mieres, J.H. Sex differences in ischemic heart disease: Advances, obstacles, and next steps. Circ. Cardiovasc. Qual. Outcomes 2018, 11, e004437. [CrossRef]

263. Bhupathy, P.; Haines, C.D.; Leinwand, L.A. Influence of sex hormones and phytoestrogens on heart disease in men and women. Women's Health 2010, 6, 77-95. [CrossRef] [PubMed]

264. Huang, A.; Kaley, G. Gender-specific regulation of cardiovascular function: Estrogen as key player. Microcirculation 2004, 11, 9-38. [CrossRef] [PubMed]

265. Borrás, C.; Sastre, J.; García-Sala, D.; Lloret, A.; Pallardó, F.V.; Viña, J. Mitochondria from females exhibit higher antioxidant gene expression and lower oxidative damage than males. Free Radic. Biol. Med. 2003, 34, 546-552. [CrossRef]

266. Colom, B.; Oliver, J.; Roca, P.; Garcia-Palmer, F.J. Caloric restriction and gender modulate cardiac muscle mitochondrial $\mathrm{H} 2 \mathrm{O} 2$ production and oxidative damage. Cardiovasc. Res. 2007, 74, 456-465. [CrossRef]

267. Justo, R.; Frontera, M.; Pujol, E.; Rodríguez-Cuenca, S.; Lladó, I.; García-Palmer, F.J.; Roca, P.; Gianotti, M. Gender-related differences in morphology and thermogenic capacity of brown adipose tissue mitochondrial subpopulations. Life Sci. 2005, 76, 1147-1158. [CrossRef] [PubMed]

268. Pinot, F.; Grant, D.F.; Spearow, J.L.; Parker, A.G.; Hammock, B.D. Differential regulation of soluble epoxide hydrolase by clofibrate and sexual hormones in the liver and kidneys of mice. Biochem. Pharm. 1995, 50, 501-508. [CrossRef]

269. Qin, J.; Le, Y.; Froogh, G.; Kandhi, S.; Jiang, H.; Luo, M.; Sun, D.; Huang, A. Sexually dimorphic adaptation of cardiac function: Roles of epoxyeicosatrienoic acid and peroxisome proliferator-activated receptors. Physiol. Rep. 2016, 4, e12838. [CrossRef] [PubMed]

270. Sinal, C.J.; Miyata, M.; Tohkin, M.; Nagata, K.; Bend, J.R.; Gonzalez, F.J. Targeted disruption of soluble epoxide hydrolase reveals a role in blood pressure regulation. J. Biol. Chem. 2000, 275, 40504-40510. [CrossRef] [PubMed]

(C) 2020 by the authors. Licensee MDPI, Basel, Switzerland. This article is an open access article distributed under the terms and conditions of the Creative Commons Attribution (CC BY) license (http://creativecommons.org/licenses/by/4.0/). 